\title{
Role of ERK1/2 MAPK Signaling in the Maintenance of Myelin and Axonal Integrity in the Adult CNS
}

\author{
Akihiro Ishii, ${ }^{1 \star}$ Miki Furusho, ${ }^{1 \star}$ ๑ Jeffrey L. Dupree, $^{2}$ and Rashmi Bansal ${ }^{1}$ \\ ${ }^{1}$ Department of Neuroscience, University of Connecticut Medical School, Farmington, Connecticut 06030 and ${ }^{2}$ Department of Anatomy and Neurobiology, \\ Virginia Commonwealth University, Richmond, Virginia 23284
}

\begin{abstract}
Oligodendrocytes form myelin during postnatal development and then maintain a functional myelin sheath throughout adult life. While many regulators of developmental myelination have been identified, the signal transduction mechanisms that regulate oligodendrocyte functions in adulthood are not well understood. The extracellular signal-regulated kinases-1 and -2 (ERK1/2), downstream mediators of mitogen-activated protein kinases (MAPKs), have emerged as prominent regulators of myelin formation. Here, we investigated whether these signaling molecules are also required for myelin maintenance in the adult CNS. Inducible conditional ablation of Erk1/2 in oligodendrocytes of the adult CNS resulted in a downregulation of myelin gene expression. Although myelin thickness was reduced and some axons were demyelinated, the majority of axons were wrapped by intact myelin sheaths that appeared structurally normal. However, late onset of progressive axonal degeneration, accompanied by astrogliosis, microglial activation, partial loss of oligodendrocytes, and functional impairment, occurred in the adult mice lacking ERK1/2 activity. Conditional ablation of Fibroblast Growth Factor receptors-1 and -2 (FGFR1/2) in oligodendrocytes also resulted in downregulation of myelin gene expression and development of axonal degeneration as the mice aged. Further, the level of the key transcription factor myelin gene regulatory factor (Myrf) was downregulated or upregulated in mice with genetic loss or gain of ERK1/2 function, respectively. Together, our studies demonstrate that ERK1/2-MAPK signaling is required for the long-term maintenance of myelin and axonal integrity in the adult CNS and suggest that FGFR1/2 and Myrf may, in part, contribute to signaling upstream and downstream of ERK1/2 in maintaining these oligodendrocyte functions during adulthood.
\end{abstract}

Key words: myelin; oligodendrocytes

\section{Introduction}

Myelin is a biologically active membrane formed by oligodendrocyte in the CNS, enabling the fast saltatory conduction of nerve impulses. Myelin biogenesis begins after birth and proceeds rapidly through the adolescent stages of life, and its structure is maintained throughout adult life. Damage or loss to the myelin sheath in demyelinating diseases, such as multiple sclerosis, results in irreversible axonal degeneration and severe neurological deficits. Given that most demyelinating diseases of the CNS occur during adulthood after myelin structure has been established, it is important to understand

Received Aug. 7, 2014; revised Sept. 18, 2014; accepted 0ct. 6, 2014.

Author contributions: A.I. and R.B. designed research; A.I., M.F., and R.B. performed research; A.I., M.F., J.L.D., and R.B. analyzed data; A.I. and R.B. wrote the paper.

This work was supported by the National Institutes of Health (grants NS38878 and NS081948) and the National Multiple Sclerosis Society (Grant RG4878A4). We thank Dr. J.S. Richards (Baylor College of Medicine, Houston, TX) for providing the Erk ${ }^{-1-}$;Erk2 floxed mice, Dr. D.M. Ornitz (Washington University) for the Fgfr1 and Fgfr 2 floxed mice, and Dr. K.-A. Nave (Max Plank Institute, Gottingen, Germany) for the Cnp-Cre mice. We would also like to thank Dr. Ben Emery (University of Melbourne, Australia) for critical reading of this manuscript and providing valuable suggestions and C. Belisario for helping with the genotyping and counting.

${ }^{*}$ A.I. and M.F. contributed equally to this work.

The authors declare no competing financial interests.

Correspondence should be addressed to Rashmi Bansal, PhD, Department of Neuroscience, University of Connecticut Medical School, 263 Farmington Avenue, Farmington, CT 06030. E-mail: bansa@@neuron.uchc.edu.

DOI:10.1523/JNEUROSCI.3360-14.2014

Copyright $\odot 2014$ the authors $\quad 0270-6474 / 14 / 3416031-15 \$ 15.00 / 0$ the molecular mechanisms that maintain the integrity of the myelin sheath and preserve axonal function during adulthood.

Conventional gene knock-out studies have shown that mice deficient in some of the major myelin structural proteins and glycosphingolipids were able to form apparently normal compact myelin but developed axonal degeneration as they aged (Coetzee et al., 1996; Griffiths et al., 1998; Yin et al., 1998; Lappe-Siefke et al., 2003; Edgar et al., 2004), suggesting that in addition to myelin formation, oligodendrocytes provide long-term trophic support to axons. More recently, inducible conditional gene knock-out studies showed that genetic ablation of the transcription factors Myrf in mature oligodendrocytes and Krox20 or Sox10 in adult Schwann cells resulted in downregulation of major myelin gene expression, demyelination, and axonal degeneration (Decker et al., 2006; Bremer et al., 2011; Koenning et al., 2012). While these studies demonstrate that continued expression of specific myelin structural components and key transcription factors is necessary for the maintenance of normal myelin structure/function and axonal integrity during adulthood, the intracellular signaling mechanisms and cell surface receptors that transduce these signals remain largely unknown.

Several genetic gain- and loss-of-function studies have revealed a prominent role of signal transduction pathways in promoting developmental myelination. Specifically, the PI3K/Akt/ mTOR pathway has been implicated in the regulation of 
oligodendrocyte development and myelin growth in the CNS (Narayanan et al., 2009; Goebbels et al., 2010; Harrington et al., 2010; Guardiola-Diaz et al., 2012; Bercury et al., 2014; LebrunJulien et al., 2014; Wahl et al., 2014). We recently showed a key role of ERK1/2-MAPK and FGFR1/2 in the regulation of myelin thickness, independent of oligodendrocyte differentiation, and initiation of myelination in the postnatal CNS (Furusho et al., 2012; Ishii et al., 2012, 2013). It is currently not known whether this is only a transient role of ERK1/2 and FGFR1/2 during developmental myelination or whether their requirement continues throughout adulthood for maintaining normal myelin and axonal integrity.

To address this question, we generated inducible, conditional transgenic mice where Erk1/2 were ablated in mature oligodendrocytes after the establishment of normal myelin structure. These mice showed downregulated transcripts of key myelin genes and the transcription factor Myrf, reduced myelin thickness, partial loss of myelin and oligodendrocytes, and, importantly, late onset of axonal degeneration, which coincided with secondary pathology and functional impairment. Similarly, conditional loss of Fgrrl/2 also resulted in downregulated myelin gene expression and delayed axonal degeneration during adulthood. These findings demonstrate an ongoing requirement for ERK1/2 and FGFR1/2 in the maintenance of myelin and axonal integrity in the adult CNS.

\section{Materials and Methods}

Mouse lines. The $E r k 1^{-/-}$mice were originally generated by Dr. P. Gilles and Dr. J. Pouyssegur (C.N.R.S, Nice, France), and Erk flox/flox $^{\text {mice were }}$ originally generated by Dr. Hedrick (University of California, San Diego, $\mathrm{CA})$, and they were bred to generate $E r k 1^{-/-}$, Erk2 $2^{\text {flox/flox }}$ transgenic mice by Dr. J.S. Richards (Baylor College of Medicine, Houston, TX). To generate mice in which the Erk2 gene was conditionally inactivated in a temporally controlled manner in an Erk1-null background, we crossed the $E r k 1^{-\prime-} ; E r k 2^{f l / f l}$ mouse line with $P l p-C r e^{E R T}$ transgenic mice expressing a tamoxifen-inducible Cre in myelinating cells (proteolipid protein; The Jackson Laboratory; Doerflinger et al., 2003) to produce progeny in which intraperitoneal injection of 4-hydroxytamoxifen (Tm; SigmaAldrich) results in Cre-mediated ablation of Erk2 in PLP-expressing oligodendrocytes (recombined oligodendrocytes). This approach provided us with a means to investigate the function of ERK1/2 signaling in myelin maintenance during adulthood, independent of their roles in the regulation of myelin thickness during developmental myelination (Ishii et al., 2012). To identify the deletion of the Erk1 allele and of the floxed region of Erk2, the primers used were described previously (Ishii et al., 2012). Mutant and control mice were analyzed from the same litters, facilitating comparisons among the genotypes. In addition to Erk1/2 double knockout (dKO) mice, other genotypes, including Erk1 or Erk2 single knockout mice, were also obtained in the crosses. Initially, all genotypes were analyzed. However, since none of the genotypes (data not shown), except the Erk1/2 dKO, showed a phenotype, the other genotypes were grouped as "controls." In the figures, we have mostly shown sunflower oil (sf)injected $\mathrm{Erk1}^{+/-}$;Erk2 $2^{\text {flox/flox }} ; \mathrm{Cre}^{+/-}$mice as "controls." The Tm-

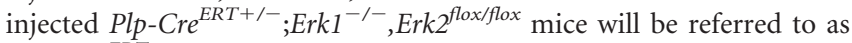
"Plp-Cre ${ }^{E R T} ;$ Erk $1 / 2 . "$

For some experiments, we also used other conditional transgenic mouse lines that we have described previously-i.e., a mouse line where Erk1/2 was conditionally ablated using Cnp ${ }^{\text {Cre+/- }}$ (Ishii et al., 2012; Lappe-Siefke et al., 2003; 2' -3' cyclic nucleotide 3' -phosphodiesterase), referred to as "Cnp-Cre;Erk1/2," and mouse lines where Erk1/2 was conditionally superactivated in CNP-expressing oligodendrocyte-lineage cells by crossing Rosa26StopFl ${ }^{\text {MekIDD,EGFP }}$ homozygote mice with Cnp $\mathrm{Cre+1-}^{\mathrm{C}}$ mice to generate heterozygous and homozygous Cnp ${ }^{\mathrm{Cre+1}+}$; Rosa26StopFl ${ }^{\text {Mek1DD,EGFP }}$ mice (Srinivasan et al., 2009; Ishii et al., 2013), referred to as "Cnp-Cre;Mek/+" and "Cnp-Cre;Mek/Mek," respectively. In addition, we have used our previously described Fgfrl/2 conditional dou- ble knock-out mouse line, which was generated by mating $F g f r f^{f l o x} / f l o x$;

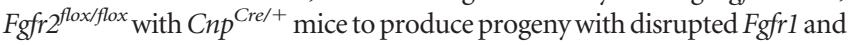
Fgfr2 genes in CNP-expressing oligodendrocyte-lineage cells and Schwann cells as demonstrated previously (Kaga et al., 2006; Furusho et al., 2009, 2012; Wang et al., 2009). For some experiments, we also generated Plp$\mathrm{Cre}^{E R T+/-} ; \mathrm{Fgfr}^{\text {flox/flox }} ; \mathrm{Fgfr} 2^{\text {flox/flox }}$ in which $\mathrm{Fgfr} 1 / 2$ were conditionally ablated during adulthood in PLP-expressing oligodendrocytes upon intraperitoneal injection of Tm. These mouse lines will be referred to here as "Cnp-Cre;Fgfrl/2" and "Plp-Cre ${ }^{E R T} ; F g$ fr $1 / 2$," respectively.

Immunolabeling. As described previously (Kaga et al., 2006, Furusho et al., 2012; Ishii et al., 2012), cryostat cross sections (15 $\mu \mathrm{m}$ ) of the cervical spinal cord, sagittal sections of cerebellum, and coronal sections of forebrain from unperfused or perfused (4\% paraformaldehyde/PBS) mice of both sexes were cut following overnight fixation in $4 \%$ paraformaldehyde/PBS and overnight cryoprotection in $20 \%$ sucrose/PBS. For some experiments nerve fibers were teased from the spinal cords for immunostaining. Sections were subjected to antigen retrieval by incubation in citrate buffer ( $\mathrm{pH} 6.0,5 \mathrm{~min}, 95^{\circ} \mathrm{C}$ ), followed by a $15 \mathrm{~min}$ incubation at room temperature. After three washes in PBS (10 min each), the slides were blocked in $10 \%$ NGS for $1 \mathrm{~h}$ and incubated in the primary antibodies (diluted in 10\% NGS/0.3\% Triton X-100) anti-pan-ERK1/2 (1:200; Promega), anti-phospho-ERK1/2 (1:400; Cell Signaling Technology), CC1 (1:40; Millipore), anti- $\beta$ APP (1:500; Invitrogen); anti-neurofilament-M (1:200; Millipore), anti-GFAP (1:1000; DAKO), anti-IBA-1 (1:1000; Wako Chemicals); and anti-cleaved caspase-3 (1:100; Cell Signaling Technology) for $24-72 \mathrm{~h}$ at $4^{\circ} \mathrm{C}$. The sections were incubated $(1 \mathrm{~h})$ in the appropriate secondary antibodies conjugated to Alexa 488 (1:500; Invitrogen) or Cy3 (1:500; Jackson ImmunoResearch), and nuclei were counterstained with Hoechst blue dye $3342(1 \mu \mathrm{g} / \mathrm{ml}$; Sigma). In some cases, the $\mathrm{ABC}$ system (Vector Laboratories) was used, and the color was developed by incubation in DAB (Sigma).

In situ hybridization. Cross sections of the cervical spinal cord, sagittal sections of cerebellum, and coronal sections of forebrain were prepared as above, and in situ hybridization was performed as previously described with minor modifications (Furusho et al., 2011, 2012; Ishii et al., 2012) using riboprobes specific for proteolipid protein (PLP) mRNA (Dr. W.B. Macklin, University of Colorado School of Medicine, Aurora, CO), myelin basic protein (MBP) mRNA (Dr. M. Qiu, University of Louisville, $\mathrm{KY}$ ), or myelin gene regulatory factor (Myrf) mRNA (Dr. Ben Emery, University of Melbourne, Australia). Briefly, after incubation in $1 \mu \mathrm{g} / \mathrm{ml}$ proteinase $\mathrm{K}$ at $37^{\circ} \mathrm{C}$ for $30 \mathrm{~min}$, sections were hybridized overnight at $65^{\circ} \mathrm{C}$ with digoxigenin-labeled antisense cRNA probe and washed twice in $50 \%$ formamide, $2 \times \mathrm{SSC}$, and $1 \%$ SDS at $65-70^{\circ} \mathrm{C}$ for $15 \mathrm{~min}$ each, followed by two washes in $100 \mathrm{~mm}$ maleic acid, $\mathrm{pH} 7.5,150 \mathrm{~mm} \mathrm{NaCl}$, and $0.1 \%$ Tween 20 at room temperature for $30 \mathrm{~min}$ each. After blocking in PBS, $0.1 \%$ Triton $\mathrm{X}-100$, and $0.2 \%$ bovine serum albumin $(1 \mathrm{~h})$, sections were incubated overnight in alkaline phosphatase-conjugated antidigoxigenin antibody (1:2000; Roche Diagnostics). Color was developed with 4-nitroblue tetrazolium chloride and 5-bromo-4-chloro-3indolylphosphate.

Electron microscopy. Transgenic and littermate control mice of both sexes were perfused with $4 \%$ paraformaldehyde and $2 \%$ glutaraldehyde in $0.1 \mathrm{M}$ cacodylate buffer, pH 7.4 (Electron Microscopy Sciences). Cervical spinal cords and cerebellum of transgenic and littermate control mice were postfixed in $1 \% \mathrm{OsO}_{4}$. Samples were dehydrated through graded ethanol, stained en bloc with uranyl acetate, and embedded in Poly/Bed812 resin (Polysciences). Semithin ( $1 \mu \mathrm{m})$ sections were stained with toluidine blue. Ultrathin $(0.1 \mu \mathrm{m})$ sections from matching areas of experimental and control tissue blocks were cut and visualized using an electron microscope (JEOL1200CX) at $80 \mathrm{kV}$. For g-ratio analysis, between 100 and 400 axons were measured per genotype from matched regions of the ventral cervical spinal cord. Statistical analysis was performed using Student's $t$ test.

$q R T-P C R$. Total RNA was extracted using the TRIzol reagent (Invitrogen) from spinal cords; $1 \mu \mathrm{g}$ of total RNA was reverse-transcribed to cDNA using the iScript Synthesis Kit (Bio-Rad) according to the manufacturer's instructions. qRT-PCR was performed using an Eppendorf Mastercycler 232 ep realplex Thermal Cycler (Eppendorf) or CFX Connect Real-Time PCR Detection System (Bio-Rad) and iQ SYBR Green 
Supermix (Bio-Rad) according to the manufacturer's instructions. qRT-PCR conditions were as follows: denaturation at $95^{\circ} \mathrm{C}, 30 \mathrm{~s}$; primer annealing at $55.5^{\circ} \mathrm{C}$ or $53^{\circ} \mathrm{C}, 30 \mathrm{~s}$; and elongation at $72^{\circ} \mathrm{C}, 40 \mathrm{~s}$. Quantification of PCR products was performed using the 2- $\Delta \Delta$ Ct method. Quantities of mRNA were normalized to the housekeeping gene GAPDH. The following primers were used: PLP forward primer, $5^{\prime}-$ GTATAGGCAGTCTCTGCGCTGAT-3'; PLP reverse primer, 5' -AAGT GGCAGCAATCATGAAGG-3'; MBP forward primer, $5^{\prime}$-TACCT GGCCACAGCAAGTAC-3'; MBP reverse primer, 5'-GTCACAAT GTTCTTGAAG-3'; myelin-associated glycoprotein $(M A G)$ forward

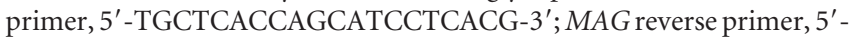
AGCAGCCTCCTCTCAGATCC-3'; cerebroside galactosyl transferase (CGT) forward primer, 5'-CAGAGGCGCTCTCCAACTC-3'; CGT reverse primer, $5^{\prime}$-GCACTCCACAGGAGCATGAA-3'; CNP forward primer, 5' - GTTCTGAGACCCTCCGAAAA-3'; CNP reverse primer, 5'-CCTTGGGTTCATCTCCAGAA-3'; Myrf forward primer, 5' -TGGCAACTTCACCTACCACA-3', Myrf reverse primer, 5'-GTGGAACCTCTGCAAAAAGC-3'; Zfp191 forward primer, 5'-GCTC AGGGATTACCGAGTTC-3'; Zfp191 reverse primer, 5'-CTCTCC AGCTGAAGCCATCT-3'; $N k x 6.2$ forward primer, $5^{\prime}$-CTTTCTCGG TAGCTGACATTCTC-3'; Nkx6.2 reverse primer, $5^{\prime}$-TCGCTGCTC TCAAACCATCC- $3^{\prime} ; N k x 2.2$ forward primer, $5^{\prime}$-CCTCCCCGAG TGGCAGAT-3'; $N k x 2.2$ reverse primer, $5^{\prime}$-GAGTTCTATCCTCTCC AAAAGTTCAAA-3'; Olig1 forward primer, 5'-GACCTCAGC CAATCTTCC-3'; Olig1 reverse primer, 5'-TAACACCCTTGA TGTTTGTACC-3'; Olig2 forward primer, 5'-TTATTA CAGACCGAGCCAACACC-3'; Olig2 reverse primer, 5' GTCGTGCATGCGCTTGCGTT-3'; Sox10 forward primer, 5' AGCCCAGGTGAAGACAGAGA-3'; Sox10 reverse primer, 5'AGTCAAACTGGGGTCGTGAG-3'; and $Y Y 1$ forward primer, 5' TTGAGCTCTCAACGAACGCTTTGC-3'; YY1 reverse primer, 5' TCAGACCCTAAGCAACTGGCAGAA-3'. GAPDH forward primer, 5' TGTGTCCGTCGTGGATCTG-3'; GAPDH reverse primer, 5'-CATGTA GGCCATGAGGTCCACCAC-3'.

Rotarod test. Mice were trained for two trials (120 s each) on the rotarod at a constant speed ( $3 \mathrm{rpm}$ ). Subsequent test runs consisted of three trials on an accelerating rotarod for up to $300 \mathrm{~s}$ (starting at $3 \mathrm{rpm}$, accelerating to a final speed of $30 \mathrm{rpm}$ ). Mice were returned to their home cages for at least 15 min between trials.

\section{Results}

ERK1/2 are expressed in mature oligodendrocytes and myelin of normal adult mice and are efficiently eliminated from $\mathrm{Plp}$-Cre ${ }^{E R T} ; \mathrm{Erk1/2}$ mice following tamoxifen injections We have previously shown that consistent with their role during developmental myelination, ERK1/2 are preferentially expressed in oligodendrocytes in normal postnatal and in young adult mice (Ishii et al., 2012, 2013). To determine whether they have ongoing function in the maintenance of myelin in older mice, we first investigated whether ERK1/2 continue to be expressed in oligodendrocytes and/or myelin of normal adult mice as they age and whether they can be affectively deleted from the adult $P l p-C r e{ }^{E R T} ;$ Erk1/2 mice after Tm injection. Therefore, at 3 months of age, when developmental myelination is established, control and $P l p-C r e^{E R T} ; E r k 1 / 2$ mice were injected intraperitoneally with tamoxifen (100 $\mu \mathrm{g} / \mathrm{g}$ body weight) or the vehicle (sunflower oil) for 8 consecutive days and analyzed at 2, 4, and 6 months post injection (MPI). Spinal cord sections, immunolabeled for pan-ERK1/2 and the oligodendrocyte marker CC1 (Fig. 1A), showed an almost complete overlap in control mice. Cell counts confirmed that ERK1/2 were expressed in $\sim 95 \%$ of $\mathrm{CC} 1+$ oligodendrocytes in 5-month-old control mice. As expected, ERK1/2 expression remained unaffected by either sunflower oil or Tm injections in the control mice. However, it was completely lost in all regions of the spinal cord white matter of Tm-injected but not sunflower oil-injected Plp-Cre $e^{E R T}$; Erk1/2 mice (Fig. 1A, B; ventral region is shown).
Interestingly, in normal adult mice, phospho-ERK1/2 immunostaining, examined from 2 to 9 months of age, was observed in a ring-like pattern closely surrounding neurofilament-positive axons in cross sections of spinal cord white matter (Fig. $1 \mathrm{Ca}-\mathrm{c}$ ). Examination of teased fibers from spinal cords showed intense staining in a pattern consistent with a preferential enriched at the paranodal region (Fig. 1d). The p-ERK1/2 staining was lost in the Tm-injected $P l p-C r e^{E R T} ; E r k 1 / 2$ mice (Fig. $1 C e$ ), confirming that it was on the myelin, not axonal, side.

We conclude that consistent with the notion that ERK1/2 signaling plays a significant role in supporting oligodendrocyte/myelin functions during adulthood, ERK1/2 activity is present in myelin of adult mice and is preferentially enriched in the paranodal cytoplasmic compartment. Furthermore, Tm administration in adult $P l p-C r e^{E R T} ; E r k 1 / 2$ mice effectively induced Cre-mediated recombination of the loxP-flanked Erk2 allele in Erk ${ }^{-1-}$ oligodendrocytes, thus eliminating ERK1/2 expression from oligodendrocytes and myelin of the adult CNS.

\section{Myelin gene expression is downregulated in $\mathrm{Plp}-\mathrm{Cre}^{E R T} ; E r k 1 / 2$ dKO mice during adulthood}

During the period of active developmental myelination, ERK1/2 are required for upregulating myelin gene expression (Ishii et al., 2012, 2013). To assess whether ERK1/2 signaling is also required for the maintenance of myelin gene expression during adulthood, we examined mRNA levels of major myelin proteins (MBP, PLP, MAG, and $\mathrm{CNP}$ ) and a lipid-synthesizing enzyme (CGT) in the spinal cords of control and $P l p-C r e^{E R T} ; E r k 1 / 2$ mice that were injected with sf or Tm at 3 months of age and analyzed at 2, 4, and $6 \mathrm{MPI}$ (Fig. $2 A, B$ ). In situ hybridization was performed simultaneously on all sections to allow overall comparisons between genotypes at different time point post-Tm injections. Note that MBP mRNA is normally expressed in both the oligodendrocyte cell bodies and the myelin sheath. Therefore, in the control sections, the strong MBP mRNA signal in the heavily myelinated adult white matter almost completely masks the signal in the cell bodies (Fig. 2A). Compared with control, the MBP mRNA signal intensity in the mutant mice was reduced at $2 \mathrm{MPI}$. By $4 \mathrm{MPI}$, the MBP transcript level declined dramatically, remaining localized in the oligodendrocyte cell bodies, but was barely visible in the myelin sheaths. By $6 \mathrm{MPI}$, a partial recovery was observed as the stronger MBP mRNA signal began to spread to the myelinated fibers. The recovery could be due to repopulation by new oligodendrocytes, which would be unrecombined, i.e., without tamoxifeninduced Cre-mediated recombination and inactivation of the floxed Erk2 allele. In addition, the outer edge of the white matter became highly vacuolated (Fig. $2 A$, arrows). Similar results were obtained for PLP mRNA expression, showing a significantly lower intensity of PLP mRNA signal per cell at $4 \mathrm{MPI}$ (Fig. $4 A$ ). Consistent with these observations, the quantification of mRNA levels by qRT-PCR showed that MBP and PLP transcript levels were progressively reduced at 2-4 MPI in the mutant mice compared with controls and partially recovered by $6 \mathrm{MPI}$ (Fig. $2 B$; controls are normalized to 1 at all time points). Similarly, the transcript levels of CNP, MAG, and CGT were also maximally downregulated in the mutant spinal cords by $4 \mathrm{MPI}$ and showed varying degrees of recovery at $6 \mathrm{MPI}$ (Fig. $2 B$ ).

To investigate whether ablation of Erk1/2 from mature oligodendrocytes in adulthood also affected other regions of the CNS, we analyzed the expression of MBP mRNA in the cerebellum and corpus callosum of control and $P l p-C r e^{E R T} ; E r k 1 / 2 d K O$ mice at 1, 2, 4, and $6 \mathrm{MPI}$ (4 MPI is shown in Fig. 7A). As was observed in the spinal cord, the intensity of MBP mRNA expression was reduced maximally by $4 \mathrm{MPI}$ in the cerebellum and corpus callosum of the mutant CNS compared with controls (Fig. 7A), indicating that the effects of 


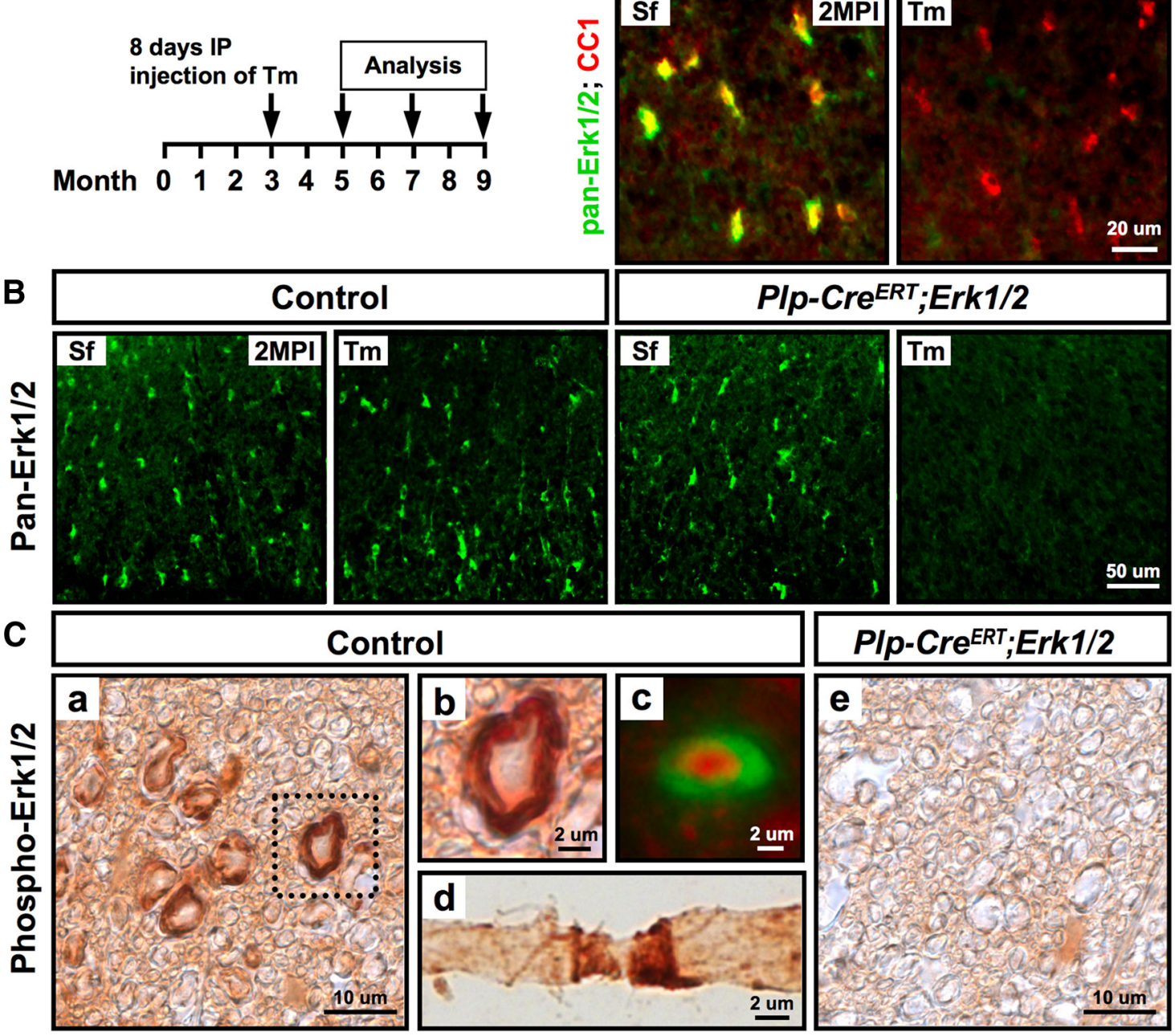

Figure 1. ERK1/2 are expressed in mature oligodendrocytes and myelin of normal adult mice and are efficiently eliminated from Plp-Cre ${ }^{E R T}$;Erk1/2 dKO mice following tamoxifen injections. Three-month-old control and PIp-Cre ${ }^{E R T}$;Erk $1 / 2$ mice were injected intraperitoneally (IP) with Sf or Tm for $8 \mathrm{~d}$. A, Cervical spinal cord sections from Plp-Cre ${ }^{E R T}$;Erk $1 / 2$ and littermate controls were double immunolabeled for the oligodendrocyte marker CC1 and pan-ERK1/2 and analyzed at 2 months post Tm injection. A complete overlap of pan-ERK1/2 and CC 1 staining (yellow) in the control and a loss of ERK1/2 from $\mathrm{CC}^{+}{ }^{+}$(red) oligodendrocytes in the Tm-injected PIp-Cre ${ }^{E R T}$;Erk1/2 mice show that ERK1/2 are expressed in mature oligodendrocytes and that they are effectively deleted after Tm injections. $\boldsymbol{B}$, Spinal cord sections from control or Plp-Cre ${ }^{E R T} ; E r k 1 / 2$ mice immunolabeled for pan-ERK1/2 and analyzed at 2 MPI with either sunflower oil or Tm show that the loss of pan-ERK1/2 staining occurs only in the Tm-injected PIp-Cre ${ }^{E R T}$;Erk1/2 mice. Ca-c, Spinal cord cross sections from 5-month-old control mice immunolabeled for phospho-ERK1/2 by either the ABC-DAB system $(\boldsymbol{a}, \boldsymbol{b})$ or immunofluorescence (c, green) show strong phospho-ERK1/2 staining in a ring-like pattern surrounding the axon, which is immunolabeled for neurofilament-m (c, red). Cd, Teased fibers from spinal cords of 2-month-old control mice show intense staining for phospho-ERK1/2 at the paranodal region of the myelinated fiber. Ce, The phospho-ERK1/2 immunolabeling was lost in the Plp-Cre ${ }^{E R T}$;Erk $1 / 2 \mathrm{dKO}$ spinal cords, demonstrating the specificity of this staining pattern for myelin. $N=3$ for each condition. Scale bars as indicated. Representative images from ventral white matter regions are shown.

ERK1/2 signaling on myelin gene expression are more generalized and not just specific to the spinal cord.

We conclude that continued ERK1/2 signaling is required in oligodendrocytes to maintain normal levels of myelin gene expression in the adult CNS.

Ablation of Erk1/2 in oligodendrocytes during adulthood results in delayed axonal degeneration and myelin abnormalities in $\mathrm{Pl} p-\mathrm{Cre}^{E R T}$;Erk1/2 dKO mice

Oligodendrocytes and myelin provide trophic support for axons (Trapp et al., 1998; Nave and Trapp, 2008). Here, we asked whether myelin function, particularly as it affects axons, is altered in the absence of ERK1/2 signaling. Toluidine staining of semithin sections (Fig. 3A) and electron microscopic (EM) analysis (Fig. 3B) of spinal cord ventrolateral white matter revealed significant myelin and ax- onal pathology at 6 MPI in Tm-injected but not sunflower oilinjected $\mathrm{Plp}$-Cre ${ }^{E R T} ;$ Erk1/2 mice. Widespread axonal degeneration was indicated by the presence of vacuoles and abnormal myelin figures, which appeared as darkly stained ovals in semithin sections (Fig. 3A, arrows). EM micrographs showed myelinated axons in different phases of degeneration, such as axons reduced to a condensed mass; redundant or collapsed myelin profiles, consistent with myelin remaining after axonal loss; and empty spaces surrounded by thin myelin, representing completely degenerated axons (Fig. $3 \mathrm{Ba}-$ d). In addition, unmyelinated axons were occasionally observed in the mutant spinal cords, suggesting that a small population of axons may be undergoing demyelination in the absence of ERK1/2 signaling (Fig. 3Be, asterisk). Generally, axons of all calibers were affected. Quantification of myelin thickness, presented as a scatterplot of g-ratio or thickness (micrometers), showed that axons in the spinal 
A

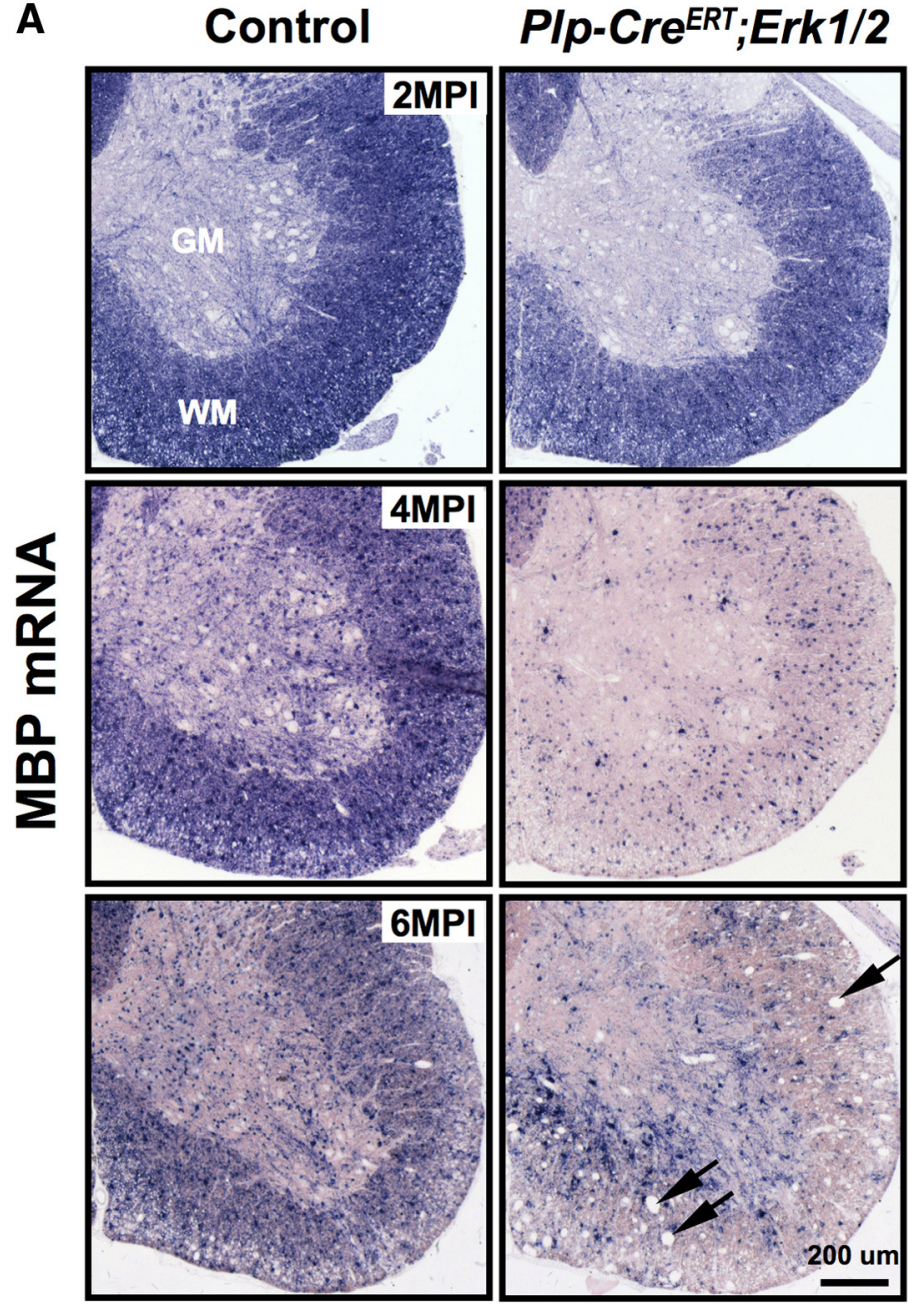

B
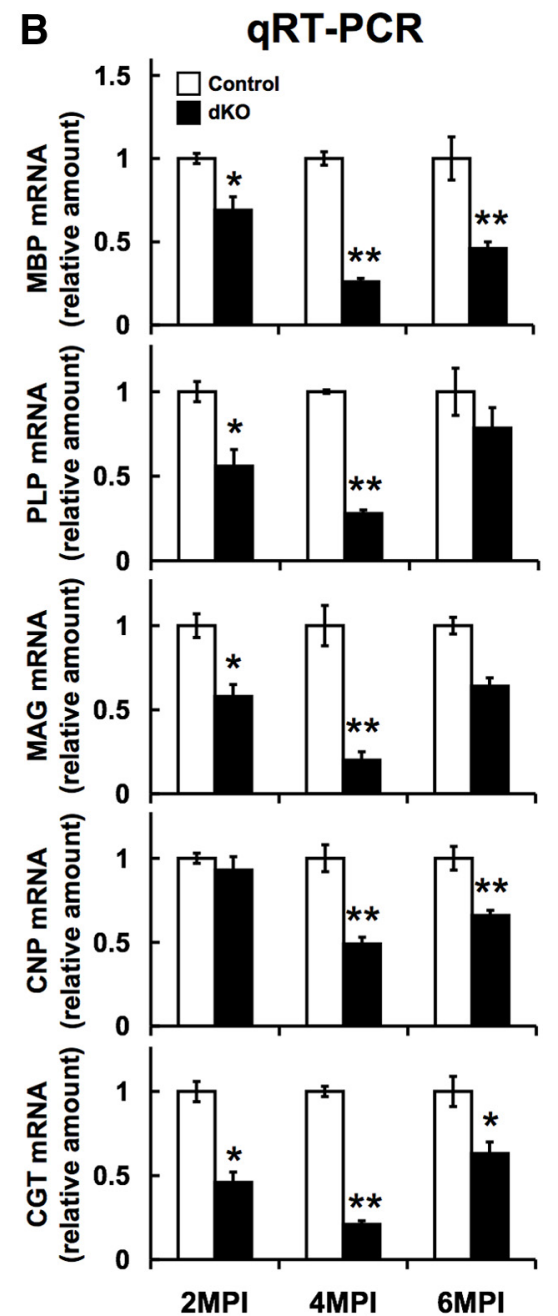

Figure 2. Myelin gene expression is downregulated in $P l p$-Cre ${ }^{E R T} ;$ Erk $1 / 2 d K O$ mice during adulthood. Spinal cord sections from control and adult $P l p$-Cre ${ }^{E R T}$; Erk $1 / 2 \mathrm{dKO}$ mice were analyzed by in situ hybridization for MBP mRNA and by qRT-PCR for MBP, PLP, MAG, CNP, and CGT mRNA expression at 2, 4, and 6 MPI of Tm to 3-month-old mice. $A$, In situ hybridization performed simultaneously on sections at all time points shows that signal intensity of MBP mRNA expression were reduced in PIp-Cre ${ }^{E R T}$;Erk1/2 dKO compared with littermate controls at all ages. At 4 MPI, MBP mRNA expression is barely detectable in the myelin sheath of mutant mice and remains largely localized to the oligodendrocyte cell bodies. At 6 MPI, partial repopulation by new unrecombined oligodendrocytes is indicated by the increase in MBP mRNA signal in PIp-Cre ${ }^{E R T} ; E r k 1 / 2 d K O$ relative to the signal at $4 \mathrm{MPI}$. Vacuoles, which appear in the white matter by $6 \mathrm{MPI}$, are indicated by arrows. $B$, Quantification of MBP, PLP, MAG, CNP, and CGT mRNA by qRT-PCR shows a significant reduction in their levels in the Plp-Cre ${ }^{E R T} ;$ Erk $1 / 2 \mathrm{dKO}$ compared with controls, reaching the lowest levels by $4 \mathrm{MPI}$ and showing varying degrees of partial recovery by $6 \mathrm{MPI}$. Controls are normalized to 1 at all time points. Error bars indicate SEM. ${ }^{*} p<0.05,{ }^{* *} p<0.01 ; N=3$ for each condition. WM, white matter; GM, gray matter. Scale bars as indicated.

cords of $P l p-C r e^{E R T} ; E r k 1 / 2 d K O$ mice were wrapped by myelin sheaths that were thinner than controls (Fig. 3C).

Similarly, EM analysis of the cerebellum showed thinner myelin sheaths in the Plp-Cre ${ }^{E R T}$;Erk1/2 dKO compared with control mice (Fig. 7C). Further, the cerebellum also displayed clear signs of myelin and axonal pathology, including degenerating axons with dense inclusions, consistent with remnants of organelles, myelin profiles, and vacuoles with membranous strands of myelin (Fig. 7C, asterisk).

We conclude that continued ERK1/2 signaling in oligodendrocytes of the adult $\mathrm{CNS}$ plays a significant role in the long-term maintenance of myelin and axonal integrity during adulthood.

\section{Viability of oligodendrocytes is partially affected at later} stages following Erk1/2 ablation in Plp-Cre ${ }^{E R T}$;Erk1/2 dKO mice

Since significant downregulation of key myelin gene transcripts occurs upon ablation of Erk1/2 in mature oligodendrocytes, we next investigated the effects of Erk1/2 loss on the viability of oligodendrocytes themselves. Spinal cord cross sections from control and Plp-
$\mathrm{Cre}^{E R T}$;Erk1/2 dKO mice at 2, 4, and 6 MPI were analyzed by in situ hybridization for PLP mRNA expression as a marker of mature oligodendrocytes. As was seen for MBP mRNA, the intensity of PLP mRNA expression by each oligodendrocyte was significantly reduced at 2-4 MPI in the mutants compared with controls (Fig. 4A). However, the numbers of PLP $\mathrm{mRNA}^{+}$oligodendrocytes were either not significantly reduced ( 2 MPI) or reduced slightly $(\sim 15 \%$ at $4 \mathrm{MPI}$ ), suggesting that although there was partial loss of oligodendrocytes in the mutants at $4 \mathrm{MPI}$, the dramatic reduction of myelin gene expression observed by qRT-PCR (Fig. 2B) must have been due primarily to a reduction in myelin gene expression per oligodendrocyte. The gray matter oligodendrocytes were also affected, as their numbers declined significantly at 4-6 MPI in the mutants compared with controls (Fig. $4 B$ ). Note that by $6 \mathrm{MPI}$, although the total numbers of oligodendrocytes showed only a slight reduction in the mutants, these numbers include the new oligodendrocytes that had repopulated the gray and white matter by this time. These new oligodendrocytes, which have not undergone Cre-mediated recombination and deletion of floxed Erk2, could easily be identified by 

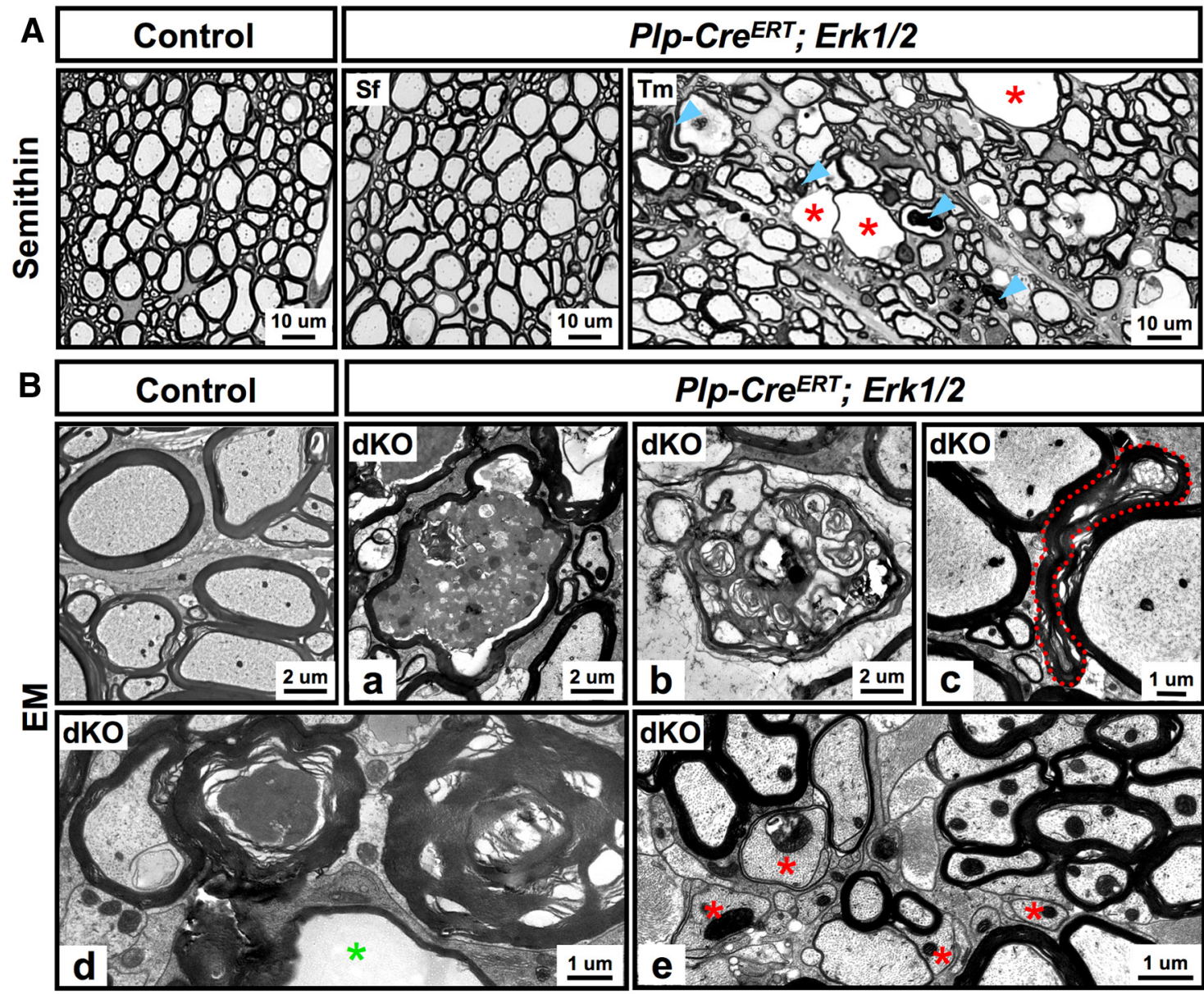

Plp-Cre ${ }^{E R T} ;$ Erk1/2
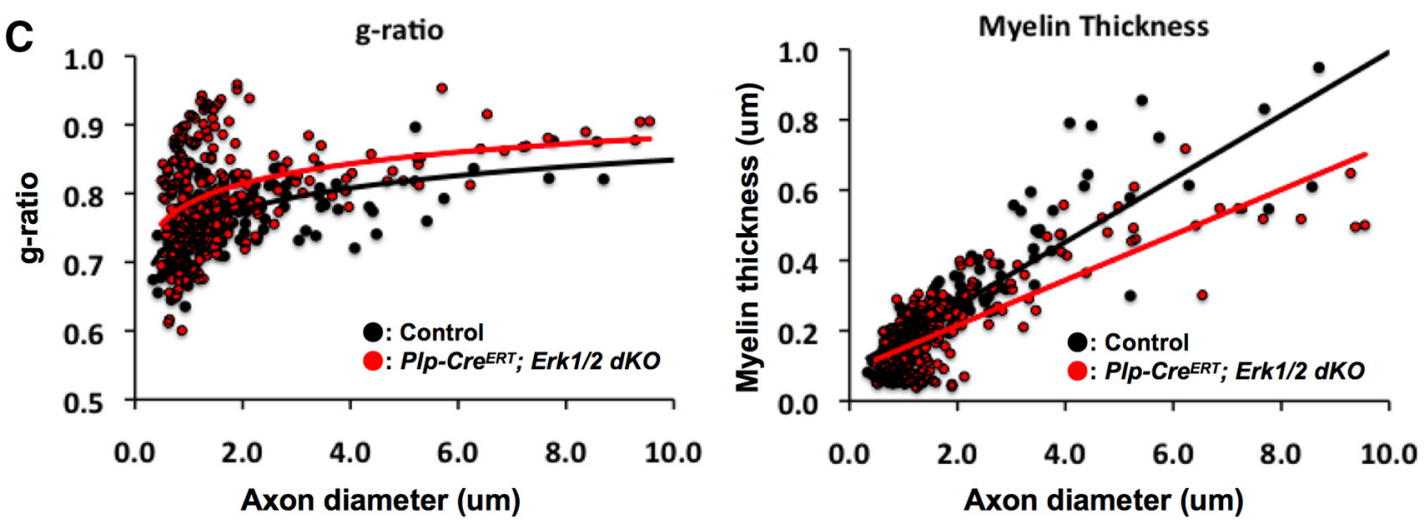

Figure 3. Ablation of Erk1/2 in oligodendrocytes during adulthood results in delayed axonal degeneration and myelin abnormalities in PIp-Cre ${ }^{E R T}$;Erk $1 / 2$ dKO mice. $A$, Transverse semithin sections of ventral spinal cord from PIp-Cre ${ }^{E R T}$;Erk $1 / 2$ and littermate control mice injected with either Tm or $\mathrm{Sf}$ at 3 months of age and analyzed at $6 \mathrm{MPI}$ show abnormal myelin profiles with darkly stained ovals (arrowheads) and degenerating axons (red asterisk), which often appeared as empty spaces surrounded by thin wraps of myelin. $\boldsymbol{B}$, High-magnification EM images of ventral spinal cords from $P I p-C r e^{E R T} ; E r k 1 / 2 d K O$ mice at $6 \mathrm{MPI}$ show myelinated axon in the late stage of degeneration, where the axon is reduced to a highly condensed mass (a); redundant or collapsed myelin profiles, representing myelin remaining after axonal loss $(\boldsymbol{b}-\boldsymbol{d})$; empty spaces ( $\boldsymbol{d}$; green asterisk) surrounded by thin myelin, representing completely degenerated axons; and unmyelinated axons ( $\boldsymbol{e}$; red asterisk). Scale bars as indicated. Multiple images of semithin and ultrathin sections from two to three mice per group were analyzed. C, Quantification of myelin thickness, presented as a scatterplot of g-ratios or thickness in micrometers in relation to respective axon diameters, shows that axons are wrapped by thinner myelin sheaths in the Plp-Cre ${ }^{E R T}$; Erk $1 / 2 \mathrm{dKOS}$ (red circles), compared with controls (black circles). Average g-ratios: control, $0.762 \pm 0.010 ; \mathrm{dK} 0,0.800 \pm 0.009, p=6.45 \times 10^{-10} ; \sim 200$ axons were analyzed from at least two mice per group.

their relatively stronger expression of PLP and MBP mRNA compared with the old Erk2-deficient recombined oligodendrocytes (compare Figs. 4A, 2A, 4 and $6 \mathrm{MPI}$ ). The partial replacement of recombined oligodendrocytes by unrecombined oligodendrocytes at 6 MPI was further confirmed by CC1/pan-ERK1/2 double labeling, which showed the appearance of ERK1/2 immunoreactivity in a population of strongly $\mathrm{CC}^{+}$oligoden- drocytes in the Tm-injected $P l p-C r e^{E R T} ; E r k 1 / 2$ mice (data not shown).

To confirm that the decrease in oligodendrocyte numbers in the $P l p-C r e^{E R T} ; E r k 1 / 2$ mice at later ages relative to controls was due to programmed cell death of ERK1/2-deficient oligodendrocytes, not simply due to the downregulation of myelin gene expression below the level of detection, we stained spinal cord sections from the mu- 

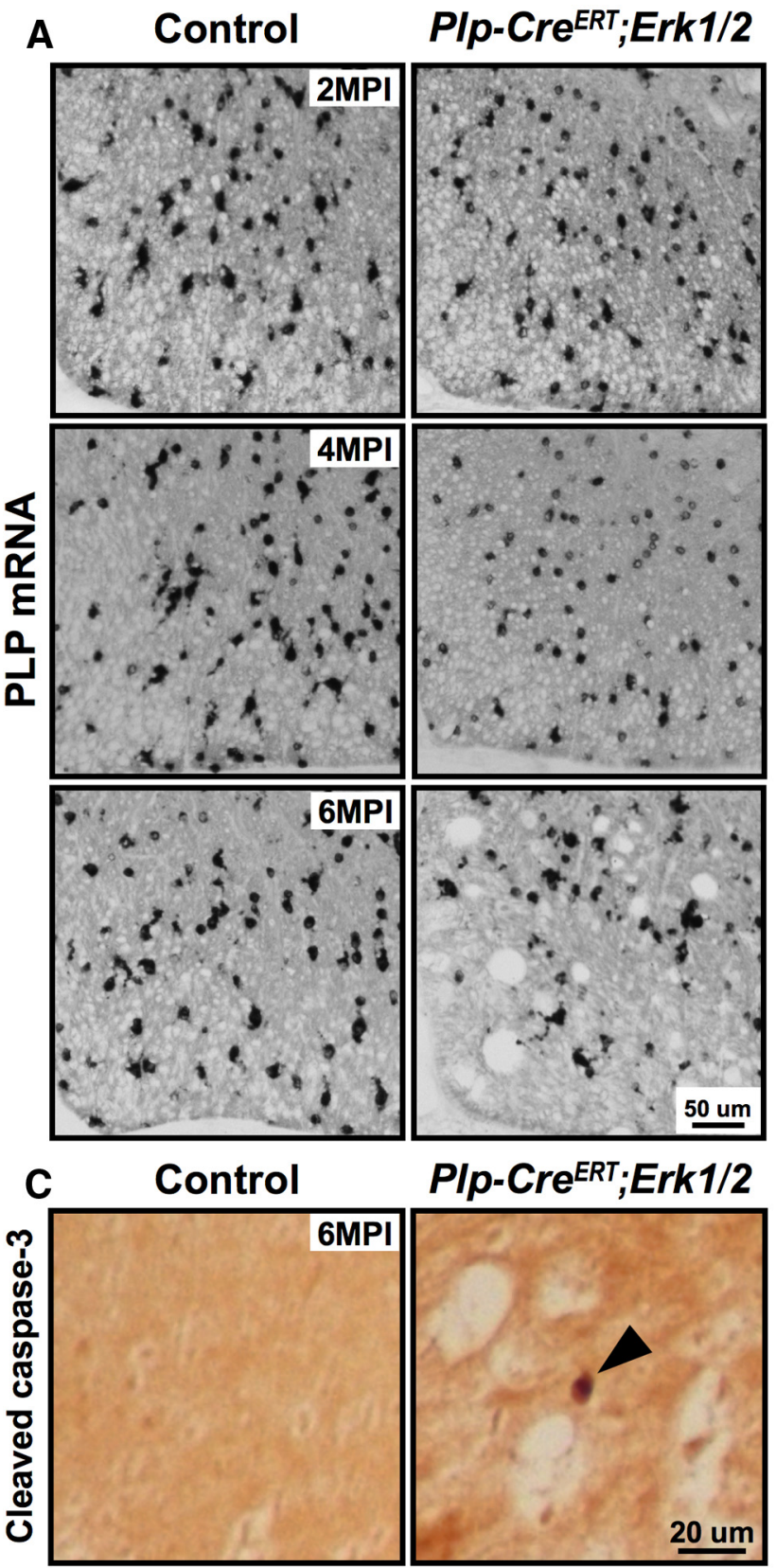

B
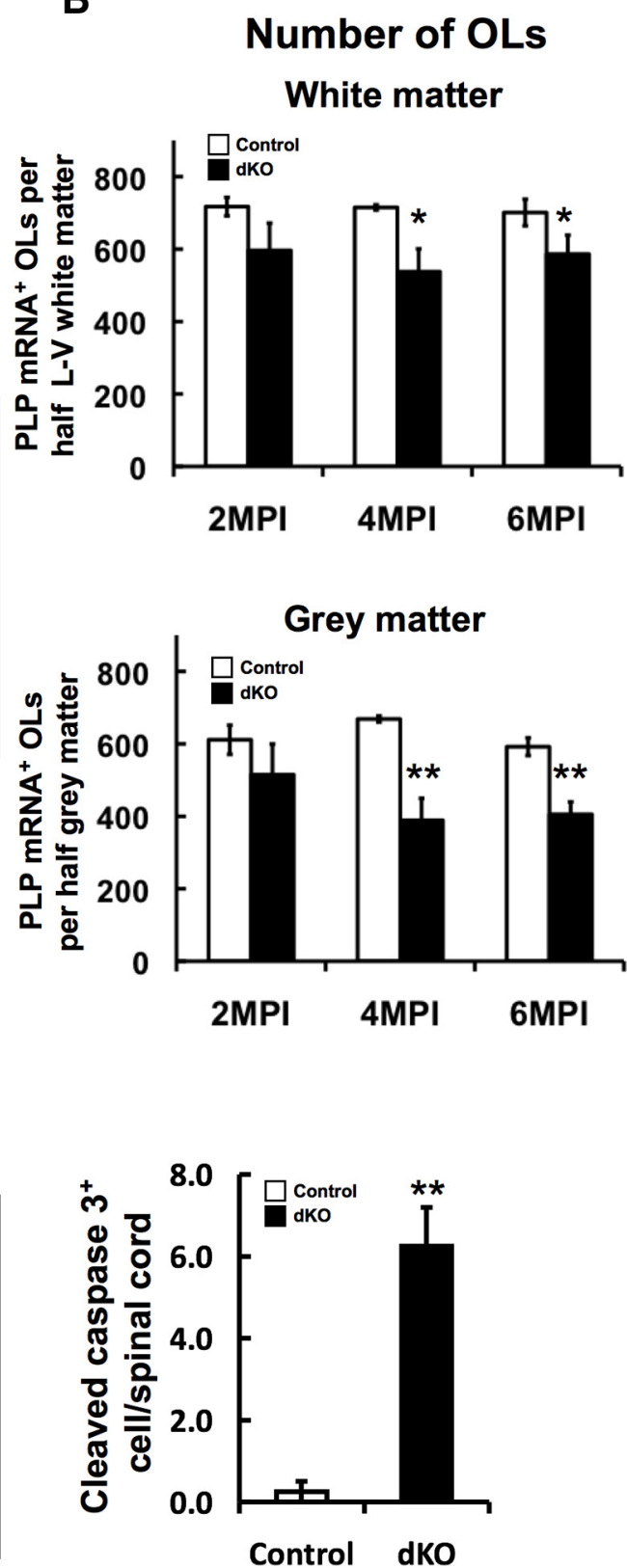

Figure 4. Viability of oligodendrocytes is partly affected at later time points after Erk1/2 ablation in $P l p$-Cre ${ }^{E R T} ; E r k 1 / 2 \mathrm{dKO}$ mice. Spinal cord sections from control and $P / p$-Cre ${ }^{E R T} ;$ Erk $1 / 2 \mathrm{mice}$ were injected with Tm at 3 months and analyzed at 2, 4, and $6 \mathrm{MPI}$ by in situ hybridization for PLP mRNA expression $(\boldsymbol{A}, \boldsymbol{B})$ and by immunolabeling for cleaved caspase-3 (C).A, The intensity of PLP mRNA per oligodendrocyte was progressively reduced in the Plp-Cre ${ }^{E R T}$; Erk $1 / 2$ dKO mice at 2- $4 \mathrm{MPI}$. B, The numbers of PLP mRNA ${ }^{+}$oligodendrocytes (0Ls), quantified in half-sections of lateral ventral $(L-V)$ white matter and gray matter, show significantly reduced numbers at 4 and $6 \mathrm{MPI}$ both in the white and gray matter. Three sections each from three mice of each genotype were analyzed. $C$, Sections immunolabeled for cleaved caspase-3 show significantly increased numbers of caspase- $3^{+}$cells in the PIp-Cre ${ }^{E R T}$;Erk1/2 dKO mice at $6 \mathrm{MPI}$, indicative of increased cell death due to apoptosis. Error bars indicate SEM, ${ }^{*} p<0.05,{ }^{* *} p<0.01 ; N=3$. Scale bars as indicated.

tant and control mice for active caspase- 3 as a marker for apoptosis (Fig. 4C). A small but significant increase in the numbers of active caspase $-3^{+}$cells in the white matter at 6 MPI was observed. These data, combined with the reduced numbers of oligodendrocytes observed in the mutants, suggest that apoptosis is a likely cause of oligodendrocyte death.

We conclude that although there is a rapid downregulation of major myelin gene expression per oligodendrocyte after loss of ERK1/2 signaling, there appears to be only a delayed and partial effect on the viability of oligodendrocytes.
Ablation of Erk1/2 in Plp-Cre ${ }^{E R T} ; E r k 1 / 2$ mice by tamoxifen injections at 1 month of age results in similar effects as ablation at 3 months

To substantiate our findings obtained by the analysis of mice where ERK1/2 were deleted at 3 months of age (above), we performed a similar analysis on mice where ERK1/2 were deleted at 1 month of age by injections of Tm for $10 \mathrm{~d}$. The animals were analyzed at 2, 4, and 6 MPI. Spinal cord sections immunolabeled for pan-ERK1/2 showed cellular staining in the white matter of the control but not Tm-injected $P l p-C r e^{E R T} ; E r k 1 / 2$ mice, demon- 
strating efficient loss of ERK1/2 in the mutant mice (Fig. 5A). In situ hybridization showed a reduction in MBP and PLP mRNA signal intensity in the $P l p-C r e^{E R T} ; E r k 1 / 2 d K O$ mice compared with littermate controls (Fig. 5B). Quantification by qRT-PCR confirmed the significant reduction in the expression levels of MBP and PLP mRNA (Fig. 5C). Analysis of semithin sections of spinal cord ventral white matter showed axonal and myelin pathology at 4 and 6 MPI. Note that no obvious pathology was observed at $2 \mathrm{MPI}$, indicating late onset of axonal degeneration (Fig. 5D). Quantification of myelinated and unmyelinated axons at 4 MPI from EM micrographs showed that $\sim 17 \%$ of axons of all calibers lacked compact myelin sheaths in the mutants compared with $4 \%$ in the controls (Fig. 5E). This suggested partial demyelination of myelinated axons rather than hypomyelination, since in the spinal cord, $>95 \%$ of axons were already myelinated by 1 month of age (time of ERK1/2 ablation). Quantification of myelin thickness showed a significant reduction in $\mathrm{Plp}-\mathrm{Cr} e^{E R T}$; Erk1/2 mice compared with littermate controls (Fig. 5F), suggesting that ERK1/2 continue to play a significant role in preserving normal myelin thickness throughout adulthood. Analysis of cerebellum from $P l p-C r e^{E R T}$; Erk1/2 mice showed similar effects as the spinal cord (data not shown).

We conclude that regardless of the time of deletion, loss of ERK1/2 activity adversely affects mature oligodendrocyte function in maintaining normal myelin and axonal integrity in the adult CNS, suggesting an ongoing requirement of ERK1/2 throughout adulthood.

\section{Microglial activation and reactive astrocytosis occur in older Plp-Cre ${ }^{E R T} ;$ Erk $1 / 2$ dKO mice}

To assess potential secondary responses, like microglia activation and reactive astrocytosis to axonal degeneration and oligodendrocyte loss, we immunolabeled spinal cord sections from control and $P l p-C r e^{E R T} ; E r k 1 / 2 d K O$ mice with antibodies against markers of microglia (IBA-1) and astrocytes (GFAP). Strong staining for IBA- 1 was observed in the dKOs at 4 MPI in the gray matter and at 6 MPI in the white matter in activated microglia characterized by thicker, shorter, and less branched processes compared with resting microglia in the controls that have thinner, longer, and more branched processes (Fig. 6A). Similarly, mutant mice also showed clear signs of reactive astrogliosis with increased expression of GFAP both in the gray and white matter (Fig. 6B). Interestingly, both of these pathological effects were observed somewhat earlier (4 MPI) in the gray matter than in white matter (6 MPI).

The cerebellum and corpus callosum were also examined for the presence of these pathological effects in $P l p-C r e^{E R T} ; E r k 1 / 2$ mice. Similar to the spinal cords, a robust microglial response was observed in these CNS regions, indicated by IBA- 1 immunostaining in the mutants compared with controls at 6 MPI (Fig. $7 B$ ). Similar results were obtained when ERK1/2 were ablated at either 1 month or 3 months of age.

We conclude that axonal/myelin pathology caused by the ablation of Erk1/2 from oligodendrocytes of the adult CNS can lead to secondary pathological effects and overall disruption of CNS homeostasis in the long run.

\footnotetext{
Progressive motor function impairment is caused at later ages by the loss of ERK1/2 signaling in Plp-Cre ${ }^{E R T}$;Erk1/2 dKO mice

Given the obvious defects in myelin/axonal integrity in the Plp$\mathrm{Cre}^{E R T} ; \mathrm{Erk1/2}$ mice, we next asked whether there were alterations of neuromotor coordination in these mice. We performed the
}

rotarod test, as a measure of motor function on control and mutant mice at 1, 4, and 6 MPI (Fig. 8). At 1 MPI, the mutant mice were able to stay on the rotating rod for the same amount of time before falling as the control mice. However, at 4 MPI, the mutant mice fell much more rapidly than controls, which became progressively worse by 6 MPI.

We conclude that the loss of ERK1/2 signaling in adult oligodendrocytes gives rise to severe deficits in motor functions, perhaps as a result of axonal degeneration.

\section{Loss of FGFR1/2 signaling in oligodendrocytes results in the downregulation of myelin gene expression and late onset of axonal degeneration in $\mathrm{Fgfr} 1 / 2 \mathrm{dKO}$ mice}

Our present findings suggest that continued ERK1/2 activation within mature oligodendrocytes is required to maintain their function of providing trophic support to axons in the adult CNS. Which extracellular signals and cell-surface receptors might be the upstream mediators that activate ERK1/2 intracellularly in oligodendrocytes? We have recently shown that like ERK1/2, FGFR1/2 signaling in oligodendrocytes is required for myelin growth (Furusho et al., 2012, Ishii et al., 2013). Further, phosphoERK1/2 levels are significantly reduced in conditional Fgfrl/2 knock-out spinal cords (Furusho et al., 2012), suggesting a potential link between FGFR and ERK1/2 signaling in oligodendrocytes. We therefore asked whether FGFR1/2 signaling is required to maintain myelin gene expression in adulthood and if its loss in oligodendrocytes would result in axonal degeneration similar to that observed in mice lacking ERK1/2. To address these questions, we examined myelin gene expression and the ultrastructure of myelinated axons in 2- to 10-month-old conditional Cnp-Cre; Fgfr1/2 dKO mice and littermate controls. Since these mice, characterized in our previous study, had shown no defects in oligodendrocyte progenitor proliferation, oligodendrocyte differentiation, or initiation of myelination during developmental myelination (Furusho et al., 2012), we deemed them suitable for investigating the effects of $\mathrm{Fgfrl} / 2$ ablation in adulthood, independent of the potential early effects on oligodendrocyte progenitors or oligodendrocytes. Nevertheless, we confirmed some of the results in the Tm-inducible $\mathrm{Plp}-\mathrm{Cr} e^{E R T}{ }^{\mathrm{F}} \mathrm{Fg} f \mathrm{r} 1 / 2$ line, where ablation of Fgfr $1 / 2$ occurred at $\sim 1$ month of age.

Spinal cords from 8-month-old conditional Cnp-Cre;Fgfr1/2 $d K O$ and control mice were examined by in situ hybridization to determine MBP and PLP mRNA expression levels. As was observed for the Plp-Cre ${ }^{E R T} ; E r k 1 / 2 d K O s$, the mRNA signal intensities were found to be reduced in the Cnp-Cre;Fgfrl/2 dKO mice compared with controls (Fig. 9A). Similarly, MBP and PLP mRNA intensities were also reduced in the Tm-injected $P l p-C r{ }^{E R T} ; \mathrm{Fg} f r 1 / 2$ $d K O s$ (Fig. 9B). The numbers of total PLP mRNA+ oligodendrocytes, however, remained unchanged, suggesting that the reduced gene expression was per oligodendrocyte (total numbers of PLP $\mathrm{mRNA}^{+}$oligodendrocytes per half lateral ventral white matter at 8 months: control $=644.7 \pm 16.8 ;$ mutant $=660.7 \pm 12$ ).

The arrest of myelin growth that was observed during developmental myelination in the Cnp-Cre; Fgfr $1 / 2 d K O$ mice continued to remain arrested in older adults, even at 14 months of age, suggesting an ongoing requirement of FGFR $1 / 2$ signaling in mature oligodendrocytes for myelin growth and maintenance throughout adult life (Fig. 9D, top; Furusho et al. 2012; Figs. 1e, 2). Importantly, examination of toluidine-stained, semithin spinal cord sections from lateral ventral white matter of Cnp-Cre; Fgfr1/2 dKO mice showed the appearance of dark ovoids and myelin swirls, indicative of axonal degeneration, starting at $\sim 5$ months of age (Fig. $9 C$, top). The presence of condensed $\beta$ APP 
A $\quad 10$ days IP injection of Tm

Month $\begin{array}{llllllll}0 & 1 & 2 & 3 & 4 & 5 & 6 & 7\end{array}$

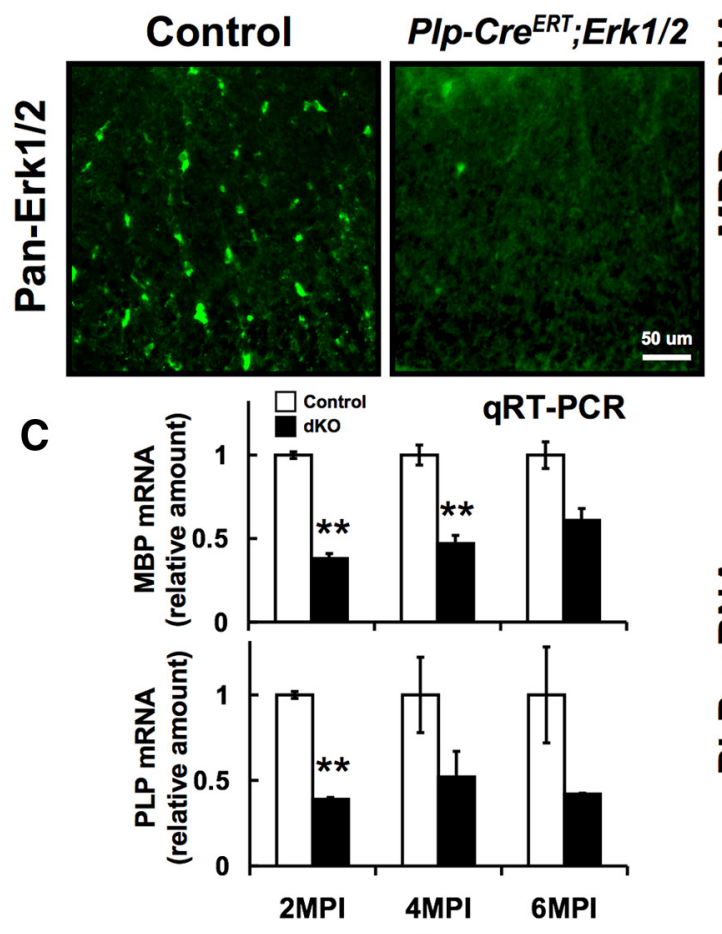

\section{B Control}
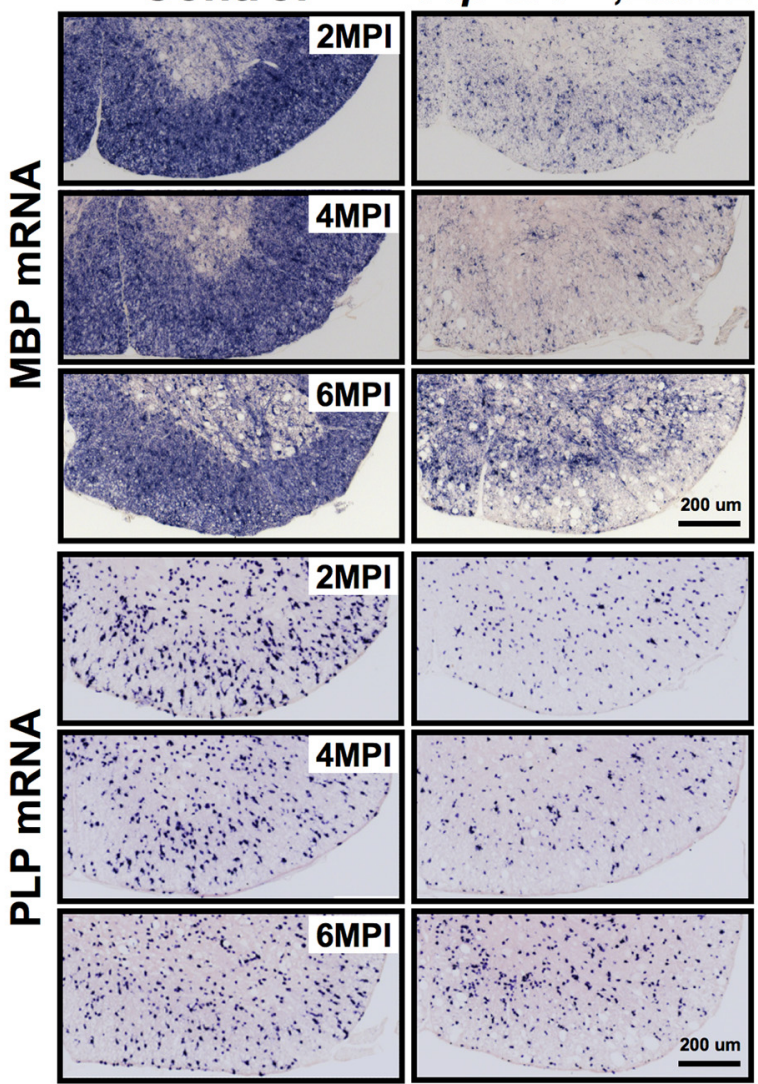

D

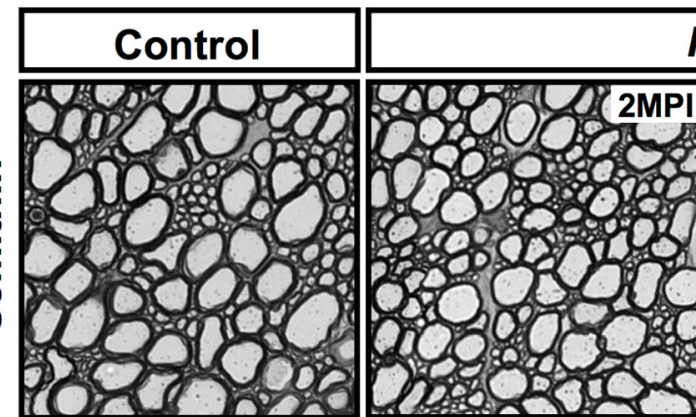

Plp-Cre ${ }^{\text {ERT; }}$ Erk1/2
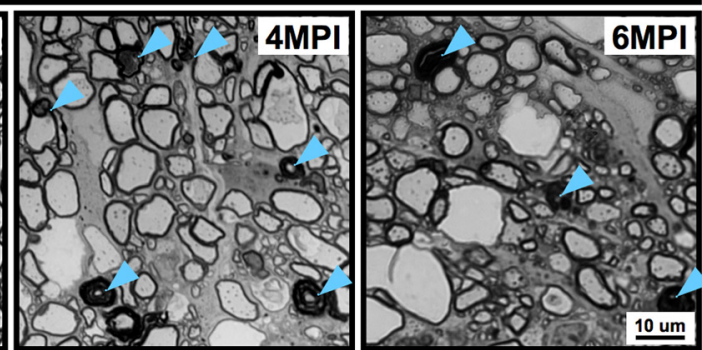

E
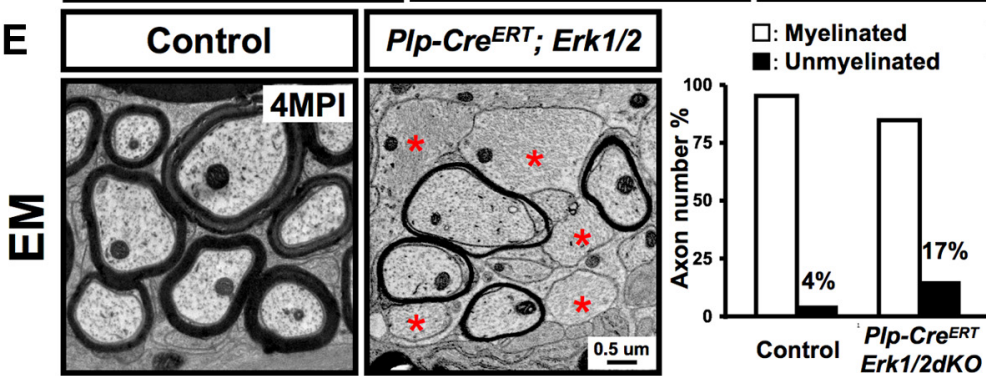

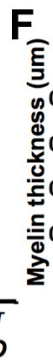

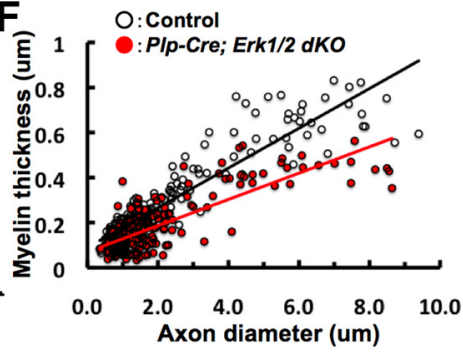

Figure 5. Ablation of Erk $1 / 2$ in $P / p$-Cre ${ }^{E R T} ;$ Erk $1 / 2$ mice by tamoxifen injection at 1 month results in similar effects as ablation at 3 months of age. $A$, Loss of pan-ERK1/2 immunolabeling (green) from the white matter of spinal cords from Tm-injected PIp-Cre ${ }^{E R T}$;Erk1/2 but not from control mice at 2 MPI shows effective deletion of ERK1/2. B, Spinal cord sections from control and PIp-Cre ${ }^{E R T}$; Erk1/2 dKO mice analyzed simultaneously at 2,4, and $6 \mathrm{MPI}$ by in situ hybridization for MBP or PLP mRNA show reduced signal intensities in Plp-Cre ${ }^{E R T}$;Erk $1 / 2 \mathrm{dKO}$ compared with littermate controls. $N=3$ mice per group. C, Quantification of MBP and PLP mRNA levels by qRT-PCR also shows a significant reduction in the expression of MBP and PLP mRNA levels in the dKOs compared with controls. Controls are normalized to 1 at all time points. Error bars indicate SEM ${ }^{* *} p<0.01 ; N=3$ for all (except for $6 \mathrm{MPI}, \mathrm{dKO} N=2$ ). D, Semithin cross sections of ventral spinal cord from PIp-Cre ${ }^{E R T}$; Erk1/2 dKO and littermate control mice at 2, 4, and 6 MPI show abnormal myelin profiles with darkly stained ovals (arrowhead) and degenerating and swollen axons with thin myelin that appeared by $4 \mathrm{MPI}$ and progressively became worse by $6 \mathrm{MPl}$ in PIp-Cre ${ }^{E R T} ;$ Erk $1 / 2 \mathrm{dKO}$ mice. E, EM analysis at $4 \mathrm{MPI}$ shows that the percentage of unmyelinated axons (red asterisk) was higher in the ventral spinal cords of $P I p$-Cre ${ }^{E R T}$; Erk1/2 dKO ( 17\%) compared with controls $(\sim 4 \%) ; 800-1000$ axons from two animals of each group were examined. $F$, Scatterplot of myelin thickness (micrometers) in relation to respective axon diameters and g-ratio analysis at $4 \mathrm{MPI}$ indicate that axons are wrapped by thinner myelin sheaths in the PIp-Cre ${ }^{E R T}$; Erk1/2 dKOs (red circles), compared with controls (black circles). Average g-ratios: control, $0.766 \pm 0.003 ; \mathrm{dK} 0,0.828 \pm 0.005, p=6.05 \times 10^{-26}$. Approximately 200 axons were analyzed from at least two mice of each group. Scale bars as indicated. 


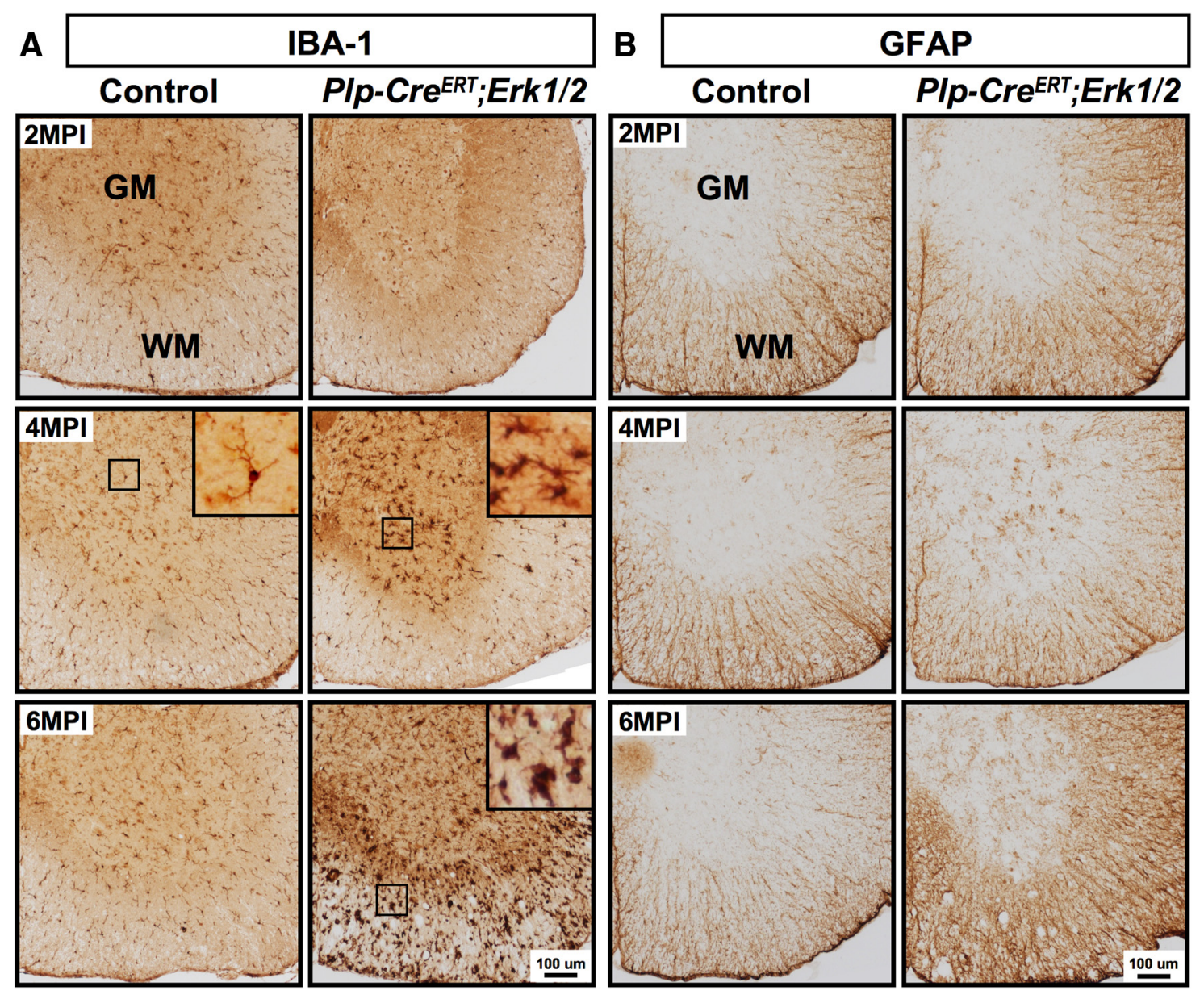

Figure 6. Microglial activation and astrocytosis occur in older PIp-Cre ;ERT Erk1/2 dKO mice. Cervical spinal cord cross sections from control and PIp-Cre ${ }^{E R T} ;$ Erk1/2 dKO mice at 2, 4, and $6 \mathrm{MPI}$ immunolabeled for IBA-1 $(\boldsymbol{A})$ or GFAP $(\boldsymbol{B})$ show presence of activated microglia and reactive astrocytes at $6 \mathrm{MPI}$ in the white matter and at $4 \mathrm{MPI}$ in the gray matter of mutant mice. Note that compared with IBA-1+ microglia in the controls that have thin, long, and highly branched processes, the activated microglia in the mutants have thicker, shorter, and less branched processes. $N=$ 3 , representative sections are shown. WM, white matter; GM, gray matter. Scale bars as indicated.

staining in these regions also indicated the occurrence of widespread axonal degeneration in mice lacking FGFR1/2 signaling (Fig. 9C, bottom). This was confirmed at the ultrastructural level by EM analysis, which showed abnormal myelin swirls and axons filled with dense bodies, indicative of degenerating axons (Fig. 9D). Increased GFAP expression, observed by immunostaining of spinal cord sections (Fig. 9E) and by immunoblotting (Fig. $9 F$ ), indicated increased astrocytosis in mice lacking FGFR1/2 signaling in oligodendrocytes. Although the Cnp-Cre;Fgfr $1 / 2$ $d K O$ mice, similar to $P l p-C r e^{E R T} ; E r k 1 / 2$ mice, showed downregulation of myelin gene expression, thinner myelin sheaths, late onset of axonal degeneration, and astrocytosis, they did not show significant microglial activation, vacuolization of the white matter, or apoptosis of oligodendrocytes (even up to 10 months of age). This less severe phenotype in the Fgfr1/2 dKO compared with $P l p-C r e^{E R T} ; E r k 1 / 2$ could be because unlike Erk1/2 knockout mice, a low level of ERK1/2 activity remains in the Fgfr1/2 $d K O$ (Furusho et al., 2012), which may prevent it from fully manifesting the Erk1/2 knock-out phenotype.

We conclude that similar to ERK1/2, continued presence of FGFR1/2 signaling in oligodendrocytes of the adult spinal cord contributes to the maintenance of normal levels of myelin gene expression and oligodendrocyte function of axonal support in adulthood.
Myrf gene expression is modulated by genetic modulation of ERK1/2 activity in oligodendrocytes of postnatal and adult spinal cords

We have shown that ERK1/2 signaling in mature oligodendrocytes regulates the transcript levels of several major myelin genes both during developmental myelination (Ishii et al., 2012) and in the adult CNS (present data). To determine whether one or more specific transcription factors known to regulate oligodendrocyte lineage cells are ultimately targeted downstream of the ERK1/2 signaling cascade, we examined spinal cords from adult control and $P l p-C r e^{E R T} ; E r k 1 / 2 d K O$ mice for the gene expression levels of a panel of transcription factors (Myrf, Zfp191, Nkx6.2, Sox10, Nkx2.2, Olig2, Olig1, and YY1). qRT-PCR analysis revealed that among all of the transcription factors analyzed at $2 \mathrm{MPI}$, only Myrf levels were significantly downregulated in the mutants (Fig. $10 A)$. This reduction in Myrf levels became even more pronounced by $4 \mathrm{MPI}$. In situ hybridization confirmed the downregulation of Myrf mRNA levels in the $\mathrm{Plp}-\mathrm{Cre}^{E R T} ; \mathrm{Erk1/2} \mathrm{dKO}$ compared with control mice (Fig. 10D).

We next asked whether the loss of ERK1/2 during developmental myelination would also affect Myrf transcript levels. qRTPCR analysis of spinal cords from Cnp-Cre;Erk1/2 $d K O$ and control mice at postnatal age $20 \mathrm{~d}$ showed that of the eight transcription factors analyzed, Myrf mRNA was the only one that was 


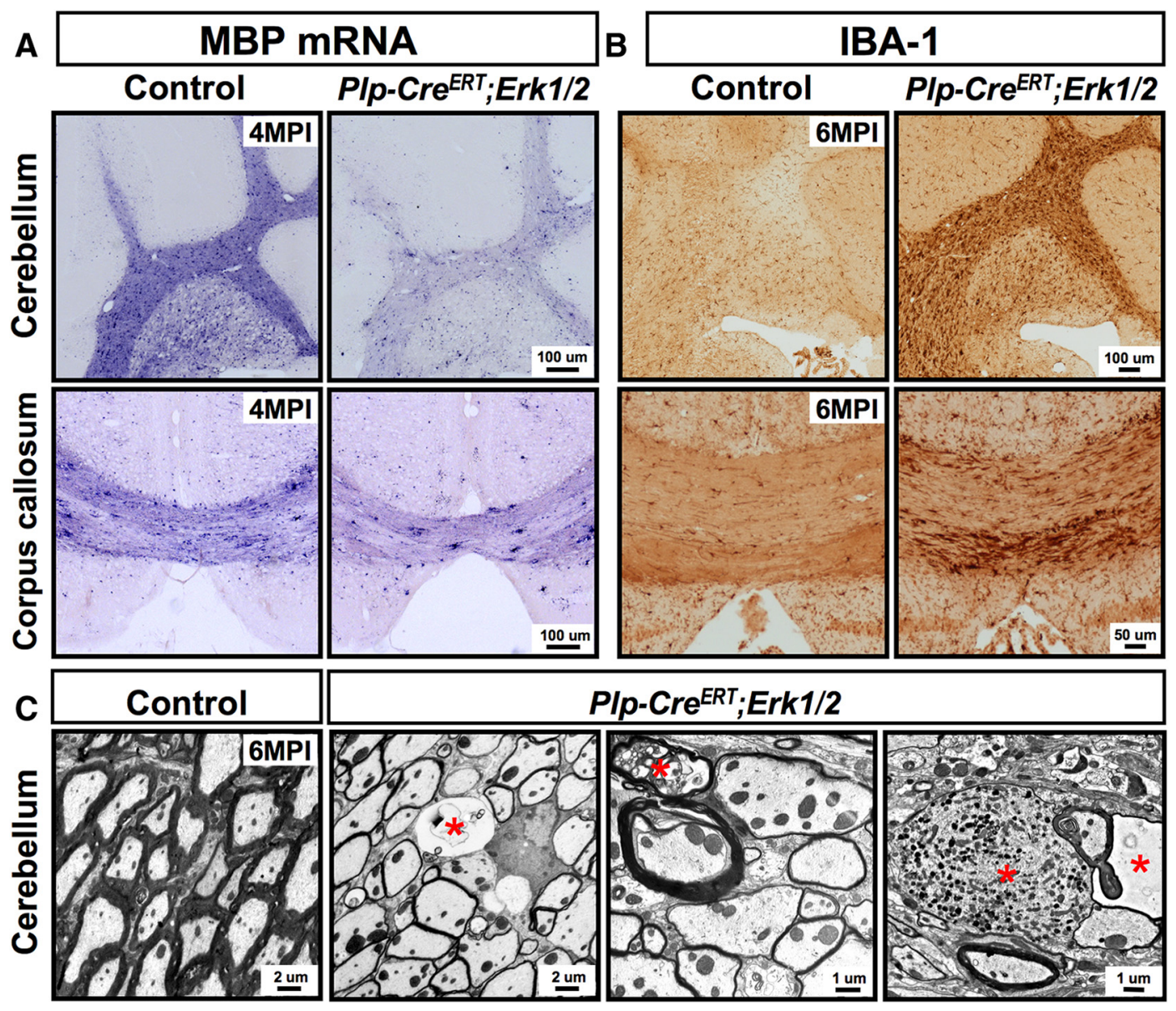

Figure 7. Downregulation of myelin gene expression, axonal pathology, and microglial activation occur in other regions of the adult CNS of Plp-Cre ${ }^{E R T}$; Erk1/2 dKO mice. A, Sagittal sections of cerebellum and coronal sections of corpus callosum from control and $P I p-C r e^{E R T} ;$; Erk $1 / 2 \mathrm{dKO}$ mice analyzed at $4 \mathrm{MPI}$ by in situ hybridization show that MBP mRNA signal intensity is reduced in mutants compared with controls. $B$, IBA-1 immunolabeling pattern at $6 \mathrm{MPI}$ is indicative of microglial activation in the cerebellum and corpus callosum of mutant compared with control mice. $C$, EM images of cerebellar peduncles shows thinly myelinated axons and axonal pathology (red asterisk) in the Plp-Cre ${ }^{E R T} ;$ Erk1/2 $d K O$ compared with control mice at 6 MPI. Scale bars as indicated. Multiple sections of each genotype were analyzed, and representative images from matched sections are shown.

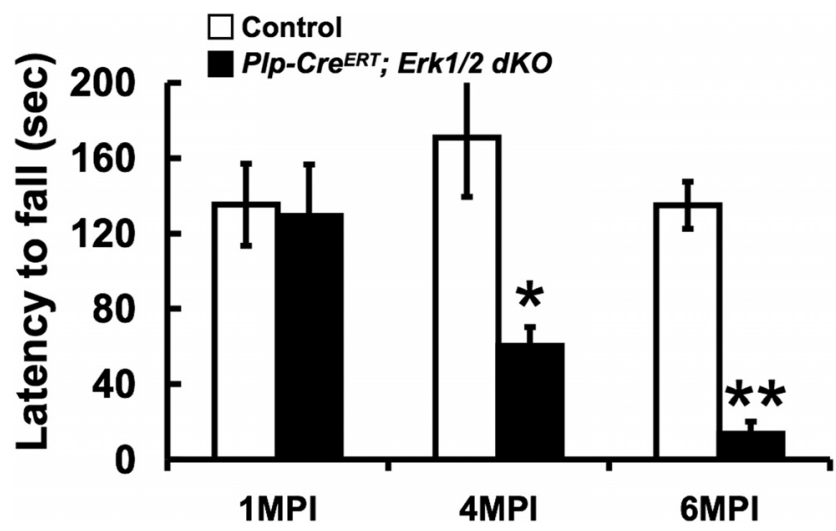

Figure 8. Progressive functional impairment is caused by the loss of ERK $1 / 2$ signaling in older PIp-Cre ${ }^{E R T} ;$ Erk $1 / 2$ dKO mice. Rotarod test was performed on PIp-Cre ${ }^{E R T} ;$ Erk $1 / 2$ dKO and littermate control mice that were Tm injected at 3 months of age and analyzed at 1,4, and $6 \mathrm{MPI}$. Significant impairment of function was noted at $4 \mathrm{MPI}$, which progressively became worse by 6 MPI. Error bars indicate SEM; ${ }^{*} p<0.05,{ }^{* *} p<0.01, N=3$.

significantly downregulated in the mutant mice relative to controls (Fig. 10B).

As a converse approach, we examined Myrf gene expression in mice where ERK1/2 levels were upregulated incrementally; i.e., in heterozygous (Cnp-Cre;Mek/+) or homozygous (Cnp-Cre;Mek/
Mek) constitutively active Mek1 transgenic mice, as described previously (Ishii et al., 2013). We found that Myrf mRNA levels increased incrementally with increasing Mek gene dosage (Fig. $10 C)$. This was confirmed by in situ hybridization, which showed increased expression of Myrf mRNA in Cnp-Cre;Mek/Mek compared with control mice (Fig. 10E).

We conclude that modulating ERK1/2 activity modulates the levels of Myrf transcripts in oligodendrocytes and that this connection between the two exists during active myelination and in the adult CNS.

\section{Discussion}

The molecular mechanisms that regulate the maintenance of myelin once it is formed are poorly understood. We have previously shown a critical requirement of ERK1/2 signaling for oligodendrocyte progenitor expansion and for promoting myelin growth during developmental myelination (Guardiola-Diaz et al., 2012; Ishii et al., 2012, 2013). Here, we demonstrate that ERK1/2 signaling is also required in oligodendrocytes throughout adulthood and is critical for the long-term maintenance of myelin and the axonal support functions of oligodendrocytes. Specifically, elimination of ERK1/2 signaling from mature oligodendrocytes in adulthood resulted in downregulation of myelin gene expression and late onset of axonal degeneration, accompanied by astro- 

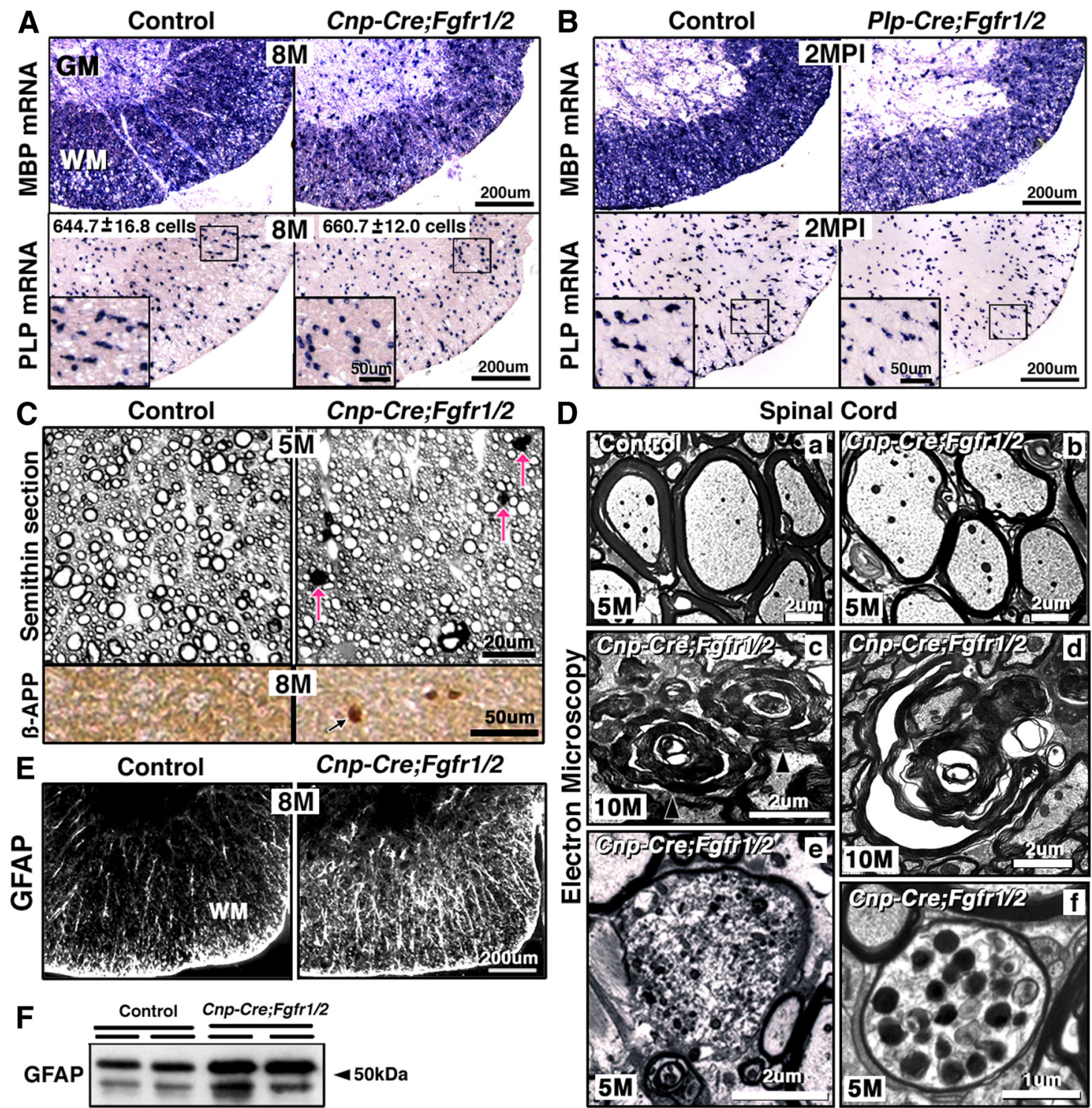

Figure 9. Loss of FGFR1/2 signaling in oligodendrocytes results in the downregulation of myelin gene expression and late onset of axonal degeneration in Fgfr $1 / 2 \mathrm{dKO}$ mice. In situ hybridization for MBP and PLP mRNA expression in spinal cord sections from 8-month (M)-old control and Cnp-Cre; Fgfr 1/2 dKO mice (A) or 3-month-old Plp-Cre ${ }^{E R T}$; Fgfr $1 / 2 \mathrm{dKO}$ mice that were analyzed at $2 \mathrm{MPI}$ of $\operatorname{Tm}(\boldsymbol{B})$ shows that the intensity of MBP and PLP mRNA expression is reduced in both the Cnp-Cre;Fgfr $1 / 2$ and Plp-Cre ${ }^{E R T} ;$ Fgfr $1 / 2$ dKO mice compared with their respective controls. The total numbers of PLP mRNA ${ }^{+}$oligodendrocytes quantified in the lateral-ventral white matter of spinal cord half-sections from control and Cnp-Cre;Fgfr $1 / 2 \mathrm{dKO}$ mice show no significant difference between the two (control $=644.7 \pm 16.8$ cells; mutant $=660.7 \pm 12$ cells). Three sections each from three mice of each genotype were analyzed. $C$, Top, Semithin cross sections of ventral spinal cords from 5-month-old control and Cnp-Cre; Fgfr 1/2 dKO mice show numerous abnormal myelin profiles with darkly stained ovals (arrows) indicative of axonal degeneration. C, Bottom, Immunohistochemistry for $\beta$-APP on spinal cord sections from 8-month-old control and (np-(re;Fgfr1/2 dKO mice shows dark condensed staining (arrows), indicative of axonal degeneration. D, EM micrographs of ventral spinal cords show that compared with control ( $\boldsymbol{a})$, the Cnp-Cre; Fffr $1 / 2 \mathrm{dKO}$ mice show thinner myelin sheaths $(\boldsymbol{b})$; redundant or collapsed myelin profiles, representing myelin remaining after axonal loss $(\boldsymbol{c}, \boldsymbol{d})$; and electron-dense bodies, indicative of axons in the process of degeneration $(\boldsymbol{e}, \boldsymbol{f})$. $\boldsymbol{E}$, Immunolabeling of spinal cord sections from control and 8-month-old Cnp-Cre;Fgfr $1 / 2 \mathrm{dKO}$ mice for the astrocytic marker GFAP shows increased expression of GFAP in the white matter of the mutant compared with control mice. $F$, Immunoblotting of equal amounts of total protein homogenates from duplicate control and mutant spinal cord samples confirms the increase in GFAP expression in the Cnp-Cre; Fgfrr $/ 2 d K 0$ mice. Scale bars as indicated. Representative images from multiple sections taken from three mice of each genotype are shown. WM, white matter; GM, gray matter.

gliosis, microglial activation, and partial loss of oligodendrocytes and myelin.

Previous genetic studies have shown that upon deletion of certain myelin structural proteins (PLP and CNP) or lipidsynthesizing enzymes (CGT), relatively normal compact myelin structures are generated. However, late onset of axonal degeneration was observed as these mice aged (Coetzee et al., 1996; Griffiths et al., 1998; Lappe-Siefke et al., 2003; Edgar et al., 2004). Therefore, the downregulation of major myelin genes observed in mice lacking ERK1/2 could in part be responsible for the late onset of axonal degeneration in these mice. Interestingly, the axonal defects that were observed in knock-outs of each of these myelin genes were more defined than in the Erk1/2 dKO. For example, in mice lacking PLP or CNP, axons of small diameter were preferentially affected, largely in the dorsal column, while in mice lacking CGT, large-diameter axons, primarily in the ventral white matter, showed axonal loss and vacuolization (Coetzee et al., 1996; Griffiths et al., 1998; Lappe-Siefke et al., 2003; Edgar et al., 2004). In contrast, the degenerative effects in mice lacking ERK1/2 were more widespread and had features similar to all of these myelin gene knock-out mice, probably because ERK1/2 regulates the expression of all of these myelin genes. Although the 


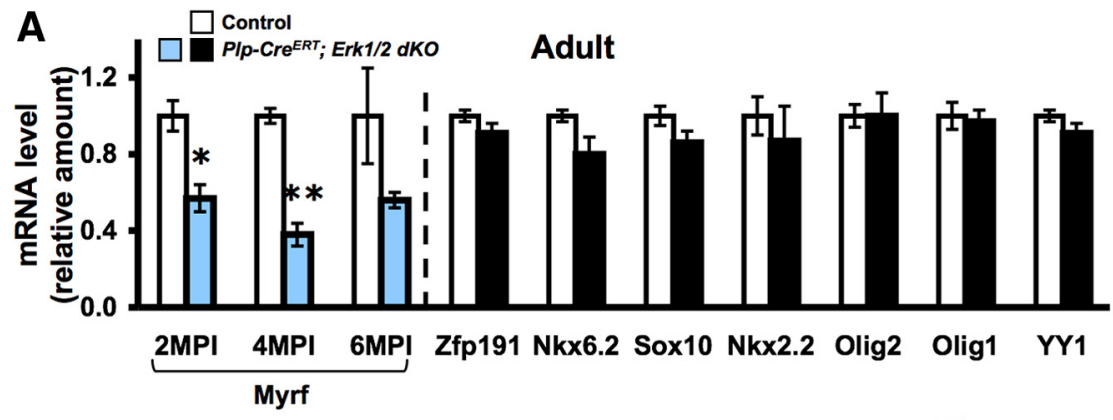

B
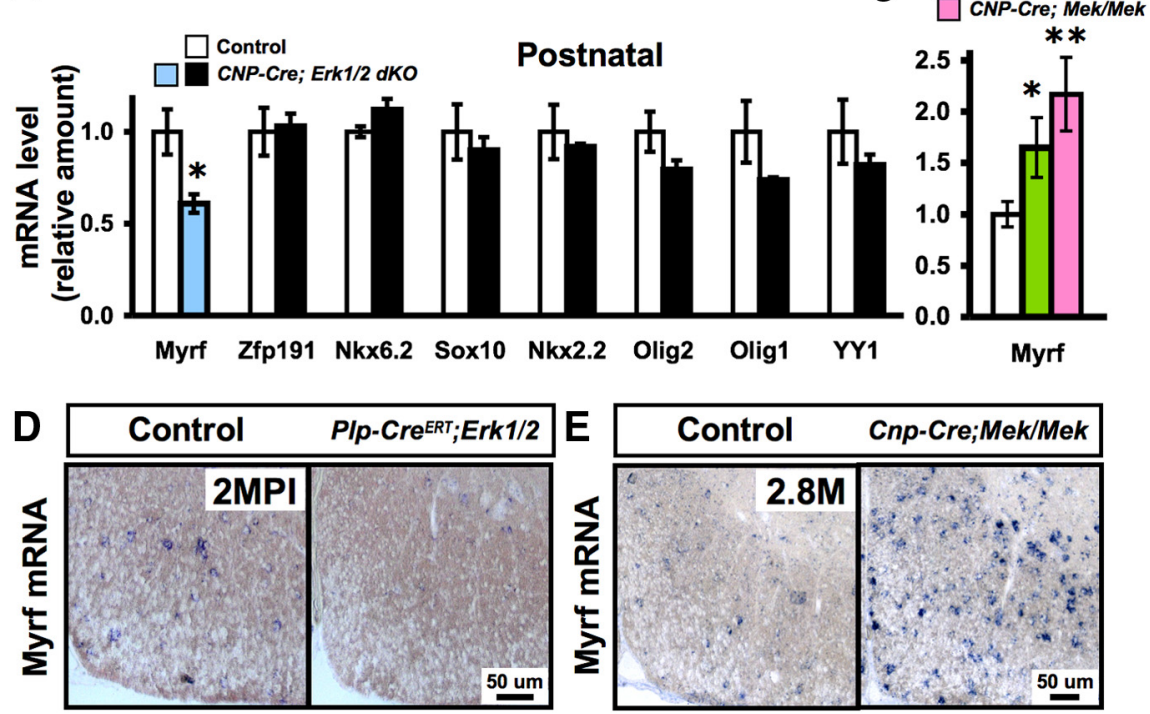

Figure 10. Myrf gene expression is modulated in transgenic mice with loss or gain of Erk1/2 function in oligodendrocytes of postnatal and adult spinal cords. A, qRT-PCR analysis of adult spinal cords at 2, 4, and $6 \mathrm{MPI}$ shows significant downregulation of Myrf mRNA levels in the PIp-Cre ${ }^{E R T} ;$ Erk1/2 dKO (blue bars) compared with littermate control mice. In contrast, Zfp191, Nkx6.2, Sox10, Nkx2.2, 0lig2, 0lig1, and YY1 mRNA levels at 2 MPI (black bars) show no significant reduction. $\boldsymbol{B}$, qRT-PCR analysis of postnatal day 20 spinal cords shows a significant reduction of Myrf transcripts in the Cnp-Cre;Erk1/2 dKO compared with the littermate controls but shows no effect on the levels of other transcription factors. C, qRT-PCR analysis shows a significant increase of Myrf mRNA levels in the spinal cords of 2.8-month-old (M) Cnp-Cre;Mek/+ and a further increase in Cnp-Cre; Mek/Mek mice compared with their littermate controls. D, In situ hybridization shows a reduction in the Myrf mRNA signal intensity in PIp-Cre ${ }^{E R T}$; Erk1/2 dKO mice at $2 \mathrm{MPI}$ and, conversely, $\boldsymbol{E}$ shows an increase in the Myrf mRNA signal intensity in the 2-2.8-month-old Cnp-Cre; Mek/Mek mice compared with their littermate controls. Scale bars as indicated. Error bars indicate SEM, ${ }^{*} p<0.05, N=3-6$ for qRT-PCR and $N=3$ for in situ hybridizations.

transcript levels of most major myelin genes were not completely lost in the Erk1/2 $d K O$ as in the specific myelin gene knock-out mice, they were significantly reduced. It is possible that a simultaneous reduction of numerous major myelin proteins and lipids in adult oligodendrocytes and myelin has a more pronounced and general effect than the complete loss of a single gene. However, the molecular mechanisms by which the loss or downregulation of myelin gene expression in oligodendrocytes could have such a profound effect on axon-glial interactions and result in axonal degeneration are not well known. Another emerging concept that is gaining much attention recently is that oligodendrocytes preserve axonal integrity by providing them with metabolic support (Fünfschilling et al., 2012; Morrison et al., 2013). Although the mechanisms of how this occurs are not well understood, it is possible that the perturbation of a major signaling pathway in oligodendrocytes, as in our Erk1/2 knock-out mice, could adversely affect the metabolic support function of oligodendrocyte, ultimately resulting in axonal degeneration.
Our data showing that ablation of Erk1/2 at different ages in adult mice resulted in similar downregulation of myelin gene expression suggest that ERK1/2 activity in oligodendrocytes/myelin is required continuously for maintaining normal levels of myelin gene expression in the adult CNS. Consistent with this notion, a strong enrichment of phospho-ERK $1 / 2$ signal was observed in the paranodal loops of myelin in the spinal cords of normal adult mice. Since the paranodes are the sites of close axon-myelin interaction, the preferential enrichment of phosphoERK $1 / 2$ at these sites is particularly significant, as it predicts a potential role of ERK1/2 signaling in transmitting or receiving local signals to or from the axons, respectively.

Although the downregulation of myelin gene expression in mutant mice occurred quite rapidly (1 MPI or less), it became most pronounced by $4 \mathrm{MPI}$, concomitant with the onset of axonal degeneration and functional disability. This downregulation was observed quite strikingly by in situ hybridization for MBP mRNA at 4 MPI. MBP mRNA, which is normally expressed both in oligodendrocyte cell bodies and in myelin sheaths, appeared to be completely lost from the myelin sheaths but remained in the oligodendrocyte cell bodies, perhaps because the MBP transcripts in the myelin membrane are less stable than in the cell body. Regardless of the reason for this reduced expression, the attenuation of MBP gene expression (or transport to the myelin membrane), combined with reduced expression of other myelin proteins and lipids, could potentially render the myelin membrane "functionally" unstable and thus insufficient to provide long-term support to axons during adult life.

Our results show that like Erk1/2 $d K O$, loss of FGFR1/2 signaling in oligodendrocytes of the adult CNS resulted in the downregulation of myelin gene expression and widespread axonal and myelin pathology as the mice aged. Given the similarities in the phenotypes of the two mutants, together with the fact that ERK1/2 activity is dramatically downregulated in the conditional Fgfr1/2 dKO (Furusho et al., 2012), it is quite likely that FGFR1/2 signaling is at least one of the potential upstream signals that regulate ERK1/2 activity in mature oligodendrocytes and thus maintain normal levels of myelin gene expression and the axonal support functions of adult oligodendrocytes. FGFs are a family of 22 members that play multiple roles in the nervous system. Although many of them are not expressed in the adult CNS, FGF-1 and FGF-2 are expressed at considerably high levels in the adult and aging CNS; in fact, these FGFs are expressed in the axons and show axolemma-bound activity (Elde et al., 1991; Matsuyama et al., 1992; Becker-Catania et al., 2011). Furthermore, FGFR1/2 and active ERK1/2 are upregulated in mature oligodendrocytes (Bansal et al., 1996; Fortin et al., 2005; Furusho 
et al., 2012), and at least FGFR2 and active ERK1/2 signals are also enriched in the cytoplasmic paranodal compartment of myelin (present data and unpublished results). Thus, given their spatial and temporal localization in vivo, it is tempting to speculate that the FGF-FGFR-ERK1/2 signaling unit at the axon-myelin interphase may play a dynamic role in maintaining the long-term integrity of myelin and axons in the adult CNS. Similarly, in the PNS, neuregulin1-ErbB2/3-PI3K-Akt-mTOR signaling at the paranodal and adaxonal cytoplasmic compartments has been proposed as the key axon-glial signaling unit (Nave, 2010; Heller et al., 2014).

Although the highest levels of myelin gene expression and the main thrust of myelination in the CNS occurs during the first month after birth, the myelin membrane continues to gradually turnover maintaining normal myelin thickness during much of adult life (Ando et al., 2003; Furusho et al., 2012). However, it is not known whether the same signaling mechanisms operate during both of these phases. Our data showing reduced myelin gene expression and myelin thickness in adult mice lacking either ERK1/2 or FGFR1/2 suggest that these molecules continue to play a significant role in preserving normal myelin thickness throughout adulthood, most likely by maintaining normal level of myelin gene expression in adult oligodendrocytes.

Since ablation of Erk1/2 downregulates the transcripts of a number of major myelin genes, it suggests that the ultimate target in the signal transduction pathway downstream of ERK1/2 should be a key transcription factor that regulates the transcription of multiple myelin genes. Our data are consistent with this notion, since out of a panel of transcription factors known to regulate oligodendrocyte lineage cells, Myrf was the only one whose transcripts were significantly downregulated in the Erk1/2 $d K O$ and, conversely, were upregulated incrementally in mice with increased ERK1/2 activity in a dose-dependent manner. Myrf directly targets and promotes the transcription of multiple oligodendrocyte-specific genes involved in myelination, including MBP, PLP, MAG, and CGT (Bujalka et al., 2013). Unlike other transcription factors, Myrf is expressed in postmitotic oligodendrocytes at a later stage of the oligodendrocyte developmental lineage (Emery et al., 2009), when ERK1/2 are also upregulated in mature oligodendrocytes (Xiao et al., 2012; Ishii et al., 2013), which correlates with the period of active myelination. Myrf, like ERK1/2, continues to be expressed in oligodendrocytes during adulthood and is critically important for myelin maintenance (Koenning et al., 2012). Furthermore, overexpression of Myrf in oligodendrocytes promotes myelin gene expression in chick spinal cords (Emery et al., 2009). Similarly, overstimulation of ERK1/2 also promotes myelin gene expression in the spinal cords of transgenic mice (Ishii et al., 2013). These studies suggest that Myrf is a key regulator of myelin gene expression; however, the upstream signals regulating Myrf transcription itself are essentially unknown. Although several molecules must contribute to the regulation of Myrf gene transcription, our findings showing that ERK1/2 activity in mature oligodendrocytes shows "rheostat-like" control in increasing or decreasing Myrf transcript levels, both during active myelination and during adulthood, suggest that ERK1/2 are among the candidates that are likely to play a prominent role upstream of Myrf in the regulation of myelin growth and maintenance.

In conclusion, ERK1/2 MAPK signaling in oligodendrocytes contributes not only to the regulation of myelin growth during developmental myelination but also to the long-term maintenance of myelin and axonal integrity in the adult CNS. Although our data point toward FGFR1/2 and Myrf as potential candidate molecules that in part may regulate and be regulated by ERK1/2, respectively, further elucidation of the complete repertoire of upstream and downstream regulators of ERK1/2 will be necessary to fully understand the molecular mechanisms that govern the maintenance of myelin and axonal integrity in the adult CNS.

\section{References}

Ando S, Tanaka Y, Toyoda Y, Kon K (2003) Turnover of myelin lipids in aging brain. Neurochem Res 28:5-13. CrossRef Medline

Bansal R, Kumar M, Murray K, Morrison RS, Pfeiffer SE (1996) Regulation of FGF receptors in the oligodendrocyte lineage. Mol Cell Neurosci 7:263-275. CrossRef Medline

Becker-Catania SG, Nelson JK, Olivares S, Chen SJ, DeVries GH (2011) Oligodendrocyte progenitor cells proliferate and survive in an immature state following treatment with an axolemma-enriched fraction. ASN Neuro 3:e00053. CrossRef Medline

Bercury KK, Dai J, Sachs HH, Ahrendsen JT, Wood TL, Macklin WB (2014) Conditional ablation of raptor or rictor has differential impact on oligodendrocyte differentiation and CNS myelination. J Neurosci 34:44664480. CrossRef Medline

Bremer M, Fröb F, Kichko T, Reeh P, Tamm ER, Suter U, Wegner M (2011) Sox10 is required for Schwann-cell homeostasis and myelin maintenance in the adult peripheral nerve. Glia 59:1022-1032. CrossRef Medline

Bujalka H, Koenning M, Jackson S, Perreau VM, Pope B, Hay CM, Mitew S, Hill AF, Lu QR, Wegner M, Srinivasan R, Svaren J, Willingham M, Barres BA, Emery B (2013) MYRF is a membrane-associated transcription factor that autoproteolytically cleaves to directly activate myelin genes. PLoS Biol 11:e1001625. CrossRef Medline

Coetzee T, Fujita N, Dupree J, Shi R, Blight A, Suzuki K, Suzuki K, Popko B (1996) Myelination in the absence of galactocerebroside and sulfatide: normal structure with abnormal function and regional instability. Cell 86:209-219. CrossRef Medline

Decker L, Desmarquet-Trin-Dinh C, Taillebourg E, Ghislain J, Vallat JM, Charnay P (2006) Peripheral myelin maintenance is a dynamic process requiring constant Krox20 expression. J Neurosci 26:9771-9779. CrossRef Medline

Doerflinger NH, Macklin WB, Popko B (2003) Inducible site-specific recombination in myelinating cells. Genesis 35:63-72. CrossRef Medline

Edgar JM, McLaughlin M, Yool D, Zhang SC, Fowler JH, Montague P, Barrie JA, McCulloch MC, Duncan ID, Garbern J, Nave KA, Griffiths IR (2004) Oligodendroglial modulation of fast axonal transport in a mouse model of hereditary spastic paraplegia. J Cell Biol 166:121-131. CrossRef Medline

Elde R, Cao YH, Cintra A, Brelje TC, Pelto-Huikko M, Junttila T, Fuxe K, Pettersson RF, Hökfelt T (1991) Prominent expression of acidic fibroblast growth factor in motor and sensory neurons. Neuron 7:349-364. CrossRef Medline

Emery B, Agalliu D, Cahoy JD, Watkins TA, Dugas JC, Mulinyawe SB, Ibrahim A, Ligon KL, Rowitch DH, Barres BA (2009) Myelin gene regulatory factor is a critical transcriptional regulator required for CNS myelination. Cell 138:172-185. CrossRef Medline

Fortin D, Rom E, Sun H, Yayon A, Bansal R (2005) Distinct fibroblast growth factor (FGF)/FGF receptor signaling pairs initiate diverse cellular responses in the oligodendrocyte lineage. J Neurosci 25:7470-7479. CrossRef Medline

Fünfschilling U, Supplie LM, Mahad D, Boretius S, Saab AS, Edgar J, Brinkmann BG, Kassmann CM, Tzvetanova ID, Möbius W, Diaz F, Meijer D, Suter U, Hamprecht B, Sereda MW, Moraes CT, Frahm J, Goebbels S, Nave KA (2012) Glycolytic oligodendrocytes maintain myelin and longterm axonal integrity. Nature 485:517-521. CrossRef Medline

Furusho M, Dupree JL, Bryant M, Bansal R (2009) Disruption of fibroblast growth factor receptor signaling in nonmyelinating Schwann cells causes sensory axonal neuropathy and impairment of thermal pain sensitivity. J Neurosci 29:1608-1614. CrossRef Medline

Furusho M, Kaga Y, Ishii A, Hébert JM, Bansal R (2011) Fibroblast growth factor signaling is required for the generation of oligodendrocyte progenitors from the embryonic forebrain. J Neurosci 31:5055-5066. CrossRef Medline

Furusho M, Dupree JL, Nave KA, Bansal R (2012) Fibroblast growth factor receptor signaling in oligodendrocytes regulates myelin sheath thickness. J Neurosci 32:6631-6641. CrossRef Medline

Goebbels S, Oltrogge JH, Kemper R, Heilmann I, Bormuth I, Wolfer S, Wich- 
ert SP, Möbius W, Liu X, Lappe-Siefke C, Rossner MJ, Groszer M, Suter U, Frahm J, Boretius S, Nave KA (2010) Elevated phosphatidylinositol 3,4,5-trisphosphate in glia triggers cell-autonomous membrane wrapping and myelination. J Neurosci 30:8953-8964. CrossRef Medline

Griffiths I, Klugmann M, Anderson T, Yool D, Thomson C, Schwab MH, Schneider A, Zimmermann F, McCulloch M, Nadon N, Nave KA (1998) Axonal swellings and degeneration in mice lacking the major proteolipid of myelin. Science 280:1610-1613. CrossRef Medline

Guardiola-Diaz HM, Ishii A, Bansal R (2012) Erk1/2 MAPK and mTOR signaling sequentially regulates progression through distinct stages of oligodendrocyte differentiation. Glia 60:476-486. CrossRef Medline

Harrington EP, Zhao C, Fancy SP, Kaing S, Franklin RJ, Rowitch DH (2010) Oligodendrocyte PTEN is required for myelin and axonal integrity, not remyelination. Ann Neurol 68:703-716. CrossRef Medline

Heller BA, Ghidinelli M, Voelkl J, Einheber S, Smith R, Grund E, Morahan G, Chandler D, Kalaydjieva L, Giancotti F, King RH, Fejes-Toth AN, FejesToth G, Feltri ML, Lang F, Salzer JL (2014) Functionally distinct PI 3-kinase pathways regulate myelination in the peripheral nervous system. J Cell Biol 204:1219-1236. CrossRef Medline

Ishii A, Fyffe-Maricich SL, Furusho M, Miller RH, Bansal R (2012) ERK1/ ERK2 MAPK signaling is required to increase myelin thickness independent of oligodendrocyte differentiation and initiation of myelination. J Neurosci 32:8855-8864. CrossRef Medline

Ishii A, Furusho M, Bansal R (2013) Sustained activation of ERK1/2 MAPK in oligodendrocytes and Schwann cells enhances myelin growth and stimulates oligodendrocyte progenitor expansion. J Neurosci 33:175-186. CrossRef Medline

Kaga Y, Shoemaker WJ, Furusho M, Bryant M, Rosenbluth J, Pfeiffer SE, Oh L, Rasband M, Lappe-Siefke C, Yu K, Ornitz DM, Nave KA, Bansal R (2006) Mice with conditional inactivation of fibroblast growth factor receptor-2 signaling in oligodendrocytes have normal myelin but display dramatic hyperactivity when combined with Cnp1 inactivation. J Neurosci 26:12339-12350. CrossRef Medline

Koenning M, Jackson S, Hay CM, Faux C, Kilpatrick TJ, Willingham M, Emery B (2012) Myelin gene regulatory factor is required for maintenance of myelin and mature oligodendrocyte identity in the adult CNS. J Neurosci 32:12528-12542. CrossRef Medline

Lappe-Siefke C, Goebbels S, Gravel M, Nicksch E, Lee J, Braun PE, Griffiths IR, Nave KA (2003) Disruption of Cnp1 uncouples oligodendroglial functions in axonal support and myelination. Nat Genet 33:366-374. CrossRef Medline
Lebrun-Julien F, Bachmann L, Norrmén C, Trötzmüller M, Köfeler H, Rüegg MA, Hall MN, Suter U (2014) Balanced mTORC1 activity in oligodendrocytes is required for accurate CNS myelination. J Neurosci 34:84328448. CrossRef Medline

Matsuyama A, Iwata H, Okumura N, Yoshida S, Imaizumi K, Lee Y, Shiraishi S, Shiosaka S (1992) Localization of basic fibroblast growth factor-like immunoreactivity in the rat brain. Brain Res 587:49-65. CrossRef Medline

Morrison BM, Lee Y, Rothstein JD (2013) Oligodendroglia: metabolic supporters of axons. Trends Cell Biol 23:644-651. CrossRef Medline

Narayanan SP, Flores AI, Wang F, Macklin WB (2009) Akt signals through the mammalian target of rapamycin pathway to regulate CNS myelination. J Neurosci 29:6860-6870. CrossRef Medline

Nave KA (2010) Myelination and support of axonal integrity by glia. Nature 468:244-252. CrossRef Medline

Nave KA, Trapp BD (2008) Axon-glial signaling and the glial support of axon function. Annu Rev Neurosci 31:535-561. CrossRef Medline

Srinivasan L, Sasaki Y, Calado DP, Zhang B, Paik JH, DePinho RA, Kutok JL, Kearney JF, Otipoby KL, Rajewsky K (2009) PI3 kinase signals BCR dependent mature B cell survival. Cell 139:573-586. CrossRef Medline

Trapp BD, Peterson J, Ransohoff RM, Rudick R, Mörk S, Bö L (1998) Axonal transection in the lesions of multiple sclerosis. N Engl J Med 338: 278-285. CrossRef Medline

Wahl SE, McLane LE, Bercury KK, Macklin WB, Wood TL (2014) Mammalian target of rapamycin promotes oligodendrocyte differentiation, initiation and extent of CNS myelination. J Neurosci 34:4453-4465. CrossRef Medline

Wang SJ, Furusho M, D'Sa C, Kuwada S, Conti L, Morest DK, Bansal R (2009) Inactivation of fibroblast growth factor receptor signaling in myelinating glial cells results in significant loss of adult spiral ganglion neurons accompanied by age-related hearing impairment. J Neurosci Res 87:3428-3437. CrossRef Medline

Xiao J, Ferner AH, Wong AW, Denham M, Kilpatrick TJ, Murray SS (2012) Extracellular signal-regulated kinase 1/2 signaling promotes oligodendrocyte myelination in vitro. J Neurochem 122:1167-1180. CrossRef Medline

Yin X, Crawford TO, Griffin JW, Tu Ph, Lee VM, Li C, Roder J, Trapp BD (1998) Myelin-associated glycoprotein is a myelin signal that modulates the caliber of myelinated axons. J Neurosci 18:1953-1962. Medline 